\title{
The Role of Striate Cortex in the Guidance of Eye Movements in the Monkey
}

\author{
Mark A. Segraves, ${ }^{1}$ Michael E. Goldberg, ${ }^{1,2}$ Shu-yi Deng, ${ }^{1, a}$ Charles J. Bruce, ${ }^{1, b}$ Leslie G. Ungerleider, ${ }^{3}$ and \\ Mortimer Mishkin ${ }^{3}$ \\ 'Laboratory of Sensorimotor Research, National Eye Institute, National Institutes of Health, Bethesda, Maryland 20892, \\ 'Department of Neurology, Georgetown University School of Medicine, Washington, DC 20007, and 'Laboratory of \\ Neuropsychology, National Institute of Mental Health, Bethesda, Maryland 20892
}

\begin{abstract}
We studied the effect of unilateral striate cortical ablations on smooth pursuit and saccadic eye movements in the monkey. The monkeys made quite accurate saccades to stationary stimuli in the field contralateral to the lesion, and they readily pursued foveal targets moving in all directions. However, when visual stimuli were stepped into the field contralateral to the lesion and then began to move, thus insuring that the moving stimulus was confined to the impaired visual hemifield, several oculomotor abnormalities emerged. Saccades to moving stimuli presented in the impaired field consistently undershot targets that moved away from the central fixation point after the step, and overshot targets that moved back towards the central fixation point. There was little or no smooth pursuit eye velocity generated in any direction to moving stimuli in the impaired field, and the monkeys could not generate smooth pursuit to stimuli maintained a few degrees from the fovea in the impaired field, although they were able to pursue such stimuli held in the normal field. Ablation of striate cortex also affected the latencies of saccades. When step-ramp stimuli were presented in the normal field, the monkeys delayed the initiation of saccades to targets moving towards the central fixation point, and hastened the initiation of saccades to targets moving away from the central fixation point. By contrast, changes in the direction of target movement did not affect the latencies of saccades into the impaired field. The deficits seemed permanent, lasting as long as the monkeys were tested-over 2 years in one case-but they were not total. Each monkey could use stimuli moving into the affected field to develop some eye velocity, although this residual ability had a much longer latency and lower gain than that provided by the intact visual system. These results show that striate
\end{abstract}

\footnotetext{
Received May 12, 1986; revised Apr. 3, 1987; accepted Apr. 7, 1987.

We thank Laura Cooper, Charles Crist, Thomas Ruffner, Geraldine Snodgrass, Alvin 7iminsky, and David Zimmerman for technical assistance; Art Hays for computer hardware support; Thelma Galkin for reconstructing the lesions; and Jean Steinberg for manuscript preparation. We are indebted to Dr. Lance $\mathbf{M}$ Optican for digital filtering software.

Correspondence should be addressed to Michael E. Goldberg, M.D., Laboratory of Sensorimotor Research, National Eye Institute, Building 10, Room 10B09, Bethesda, MD 20892.

a Present address: Institute of Biophysics, Academia Sinica, Beijing, Peoples Republic of China.

${ }^{b}$ Present address: Section of Neuroanatomy, Yale University School of Medicine, New Haven, CT 06510.

0270-6474/87/103040-19\$02.00/0
}

cortex is intimately involved in the estimation of stimulus velocity critical to the genesis of smooth pursuit and saccadic eye movements.

Monkeys (Barmack, 1970; Newsome et al., 1985) and humans (Rashbass, 1961; Robinson, 1973) can make accurate eye movements to moving targets in the periphery. Typically, these movements include a saccade, to place the eyes on target, and smooth pursuit movements that match eye velocity to target velocity. To capture the moving target accurately, the monkey must program the saccade, not to where the target is when its position enters the oculomotor system, but rather to an estimate of where the moving target will be at the end of the saccade. Thus, both smooth pursuit and saccadic systems require access to information about target velocity (Robinson, 1965, 1973).

When the eye is still, the velocity of the target in space equals the velocity of its image on the retina. However, as the eye begins to move, the velocity of the image on the retina no longer matches its velocity in space, and the pursuit system must use factors other than retinal motion to calculate appropriate eye velocity. The position error, the distance from the stimulus to the fovea, has been proposed as a parameter used by the pursuit system to generate eye velocity. Evidence for this is that humans develop pursuit movements in response to parafoveal afterimages (Heywood and Churcher, 1971; Kommerell and Täumer, 1972) and parafoveally stabilized images alone can induce or maintain smooth pursuit in humans (Pola and Wyatt, 1980) and at least maintain it in monkeys (Lisberger and Westbrook, 1985).

In the primate, motion detection appears to be mediated by visual cortex. The retina and lateral geniculate nucleus have no neurons tuned for direction of motion, and the superior colliculus has very few such motion-sensitive cells (Goldberg and Wurtz, 1972). Cells in striate cortex, on the other hand, are tuned for speed and direction of moving targets (Hubel and Wiesel, 1968; Wurtz, 1969a), and presumably the processing for motion detection originates here. We therefore inquired whether the monkey needs its striate cortex to use target motion or position to compute an appropriate eye velocity.

In the experiments described below, we studied smooth pursuit movements and saccades in rhesus monkeys with unilateral lesions of striate cortex. We not only examined foveal smooth pursuit, but also used several tasks in which the pursued target was confined to a single visual hemifield. We found that monkeys with unilateral striate lesions can perform foveal smooth 
pursuit in any direction, but they cannot use the position or the velocity of a target in the field contralateral to the lesion to produce an accurate eye velocity. In addition, we analyzed the latencies and amplitudes of saccades to targets that were stepped into one visual hemifield and then moved. We found that the monkeys could not utilize the velocity of a moving target to adjust the amplitude of their saccades to ensure accurate foveation of the moving target after the saccade.

Preliminary reports of these experiments have been presented elsewhere (Goldberg et al., 1982; Segraves et al., 1983, 1986).

\section{Materials and Methods}

Surgery and histology. Four rhesus monkeys (Macaca mulatta) underwent unilateral ablation of the striate cortex. At the time of surgery, which was performed under aseptic conditions, the monkey was anesthetized with ketamine hydrochloride $(10 \mathrm{mg} / \mathrm{kg}, \mathrm{i} . \mathrm{m}$.) followed by pentobarbital to effect (i.v., supplemented as needed), and treated with atropine sulfate $(0.04 \mathrm{mg} / \mathrm{kg}$, i.m.) to prevent excess secretion in the bronchial tracts and mouth. The left or right occipital lobe was exposed by removal of a bone flap, and the ablation, made by aspiration of tissue with a small-gauge metal suction tube, was performed under visual control with the aid of an operating microscope. Heart rate, respiration rate, and body temperature were continuously monitored throughout the procedure and maintained within the normal physiological range. Following the ablation, the dura was sewn, the bone flap replaced, and the wound closed in anatomical layers. The monkey was then placed in a warm neonatal incubator until it awakened from anesthesia. Immediately after surgery, the monkey was given gentamicin sulfate $(5$ $\mathrm{mg} / \mathrm{kg}$, i.m., daily for $5 \mathrm{~d}$ ) as a prophylactic measure against infection, and dexamethasone phosphate $(0.4 \mathrm{mg} / \mathrm{kg}, \mathrm{i} . \mathrm{m}$.) to minimize brain edema.

Initially the monkeys appeared to be hemianopic, totally neglecting the visual field contralateral to the lesion. However, during the 3 months or more that they were allowed to recover from the surgery, the neglect gradually subsided, so that it was difficult to detect any visual field defect by gross observation. After the recovery period, devices to facilitate head-holding and eye-position monitoring were implanted in a second sterile surgical procedure, using similar prophylactic antibiotic and anesthetic methods, but no steroid treatment. In 2 monkeys (M9 and M1 1), epoxy-silver-silver chloride electrodes (Bond and Ho, 1970) were implanted periorbitally for the measurement of DC electrooculograms (EOG). The remaining 2 monkeys (M19 and M23) were fitted with subconjunctival wire coils for measurement of eye position with the magnetic search coil technique (Robinson, 1963; Judge et al., 1980). All quantitative data in this study are from the 2 monkeys with implanted eye coils, although similar qualitative observations were made in the monkeys whose eye movements were monitored with EOG electrodes. The monkeys were studied behaviorally for between 9 and 27 months after the ablations.

At the conclusion of the experiment, the monkeys were given a lethal dose of pentobarbital and perfused intracardially with saline, followed by $10 \%$ formalin. The brains were then removed, photographed, embedded in celloidin, and sectioned in the frontal plane at $25 \mu \mathrm{m}$. Every tenth section was mounted and stained with cresyl violet.

Histological examination of the brains indicated that the ablation of striate cortex was complete in each case (Fig. 1). Damage to prestriate cortex was minimal, invading only the representation of the vertical meridian of area V2 at the striate-prestriate border and the representation of the far peripheral visual field of V 2 medially within the anterior portion of the calcarine fissure (Gattass et al., 1981).

In each case, the dorsal lateral genticulate nucleus (dLGN) ipsilateral to the striate lesion underwent total retrograde degeneration, with the exception of a few remaining scattered neurons, confirming the completeness of the striate removals (Fig. 2). The few remaining neurons were presumably either the dLGN cells that project to prestriate cortex (Wong-Riley, 1976; Benevento and Yoshida, 1981), which are known to survive striate removal (Yukie and Iwai, 1981), or Golgi type II interneurons (Pasik et al., 1973). As shown in Figure 2, the dLGN on the side of the lesion was not only virtually devoid of neurons, but was also markedly shrunken relative to the dLGN on the side of the intact striate cortex. It was striking that one of the genticulate nuclei shown in Figure 2 maintained a laminar structure, but examination of the sections at higher power (Fig. 3) revealed a dearth of neurons within the gliotic laminar structure.

In addition to retrograde degeneration in the dLGN, all monkeys showed a small amount of neuronal loss and gliosis in the anterior portion of the inferior pulvinar on the side of the ablation as a consequence of the damage to medial prestriate cortex in the calcarine fissure.

Behavioral testing. All behavioral control and data collection were performed with a PDP-11 computer and an on-line software system (MONK11) that has been described elsewhere (Goldberg, 1983). Eye position was recorded using a CNC Engineering search coil system, sampled at $1 \mathrm{kHz}$ with a 10 -bit Data Translation analog-digital conversion system with sensitivity set at one bit $=5^{\prime}$ of arc. After recovery from all surgery the monkeys were first trained to fixate a spot of light for a liquid reward, using techniques described previously (Fuchs, 1967; Wurtz, 1969b; Sparks and Holland, 1975; Goldberg, 1983). The spot, which was rear-projected onto a screen from a yellow or orange lightemitting diode, was $0.25^{\circ}$ in diameter, with a brightness of $0.4 \log$ units above a background of $1 \mathrm{~cd} / \mathrm{m}^{2}$. The eye coil signal was calibrated by requiring that the monkey look at various targets within the range $\pm 20^{\circ}$ from the fovea, and correlate coil signal with target position. In this range, the coil produced an approximately linear signal reproducible within $15^{\prime}$ of arc. The light spot was moved by a pair of servocontrolled mirror galvanometers (General Scanning) driven by analog signals synthesized by 12-bit digital-to-analog converters under the control of the computer. The performance of the mirror system was calibrated by comparing the command signal to the mirror with the feedback signal from the mirror. During ramp movement, there was no measurable difference (to $5^{\prime}$ of arc) between the signals. The mirror showed a lag during step movements such that a $20^{\circ}$ saccade had a lag of $8 \mathrm{msec}$ from the signal step to the end of the mirror step. Stimulus-position records were generally copies of the signal sent to the mirror.

Five eye-movement paradigms were used. Each paradigm began with the monkey looking at the fixation point. The monkey was rewarded for maintaining its eye in a window around the target such that the sum of the horizontal and vertical differences between eye and target position was less than $5^{\circ}$ for the duration of the trial. This was a criterion that the monkeys met easily and usually surpassed. If the monkey left the window, the trial was terminated without reward. Trials usually lasted $2-3$ sec. For longer trials the monkey was rewarded after unpredictable intervals averaging 2-3 sec in length. When the spot moved discontinuously and the monkey had to make a saccade, the monkey had to reenter the window within $500 \mathrm{msec}$.

The individual paradigms were as follows:

1. Saccades to and pursuit of step-ramp targets. The target was moved instantaneously $5^{\circ}-20^{\circ}$ away from the fixation point (step) and was at a constant velocity (ramp). Ramp velocities ranged from $20^{\circ}$ to $40^{\circ} / \mathrm{sec}$. Target position was upgraded at $1 \mathrm{kHz}$. Two types of step and ramp combinations were used. In one, the target was stepped horizontally, and the ramp movement was either away from the fovea ("ramp away") or towards it ("ramp back"). In the other, the target was stepped obliquely and the ramp movement was vertical. If the ramp velocity was zero, the task became a simple saccade task.

2. Sinusoidal smooth pursuit. The target spot was moved horizontally back and forth with sinusoidally varying velocity. Target position was upgraded by the computer at a frequency of $500 \mathrm{~Hz}$. Maximum excursion peak to peak was $60^{\circ}$, and the line of movement could be positioned at any angle. The highest target velocity in any of our paradigms was $125 \% \mathrm{sec}$.

3. Maintenance of pursuit movements by quasistabilized images. This paradigm began with the monkeys performing foveal pursuit of a ramp stimulus. At some time after the pursuit had become established, the fixation point was stepped $1^{\circ}$ to $5^{\circ}$ into either hemifield. Every millisecond thereafter, target position was calculated by adding the step to the eye position to approximate a stabilized image, rather than by using the calculation of the ramp function needed to drive the mirror. We found that the addition of a small signal proportional to eye velocity tended to overcome the lag of the galvanometer-controlled mirror and gave a better approximation of eye position. As a result, the actual signal fed to the mirror was

$$
s(t)=e(t)+a+k v(t)
$$

where $s(t)$ is stimulus position at time $t, e(t)$ is eye position at time $t, a$ is the predefined offset between eye and stimulus, $k$ is a constant, usually 0.125 , and $v(t)$ is eye velocity at time $t$. Eye velocity was computed digitally on-line by the method of Van Gisbergen et al. (1981). This 
A
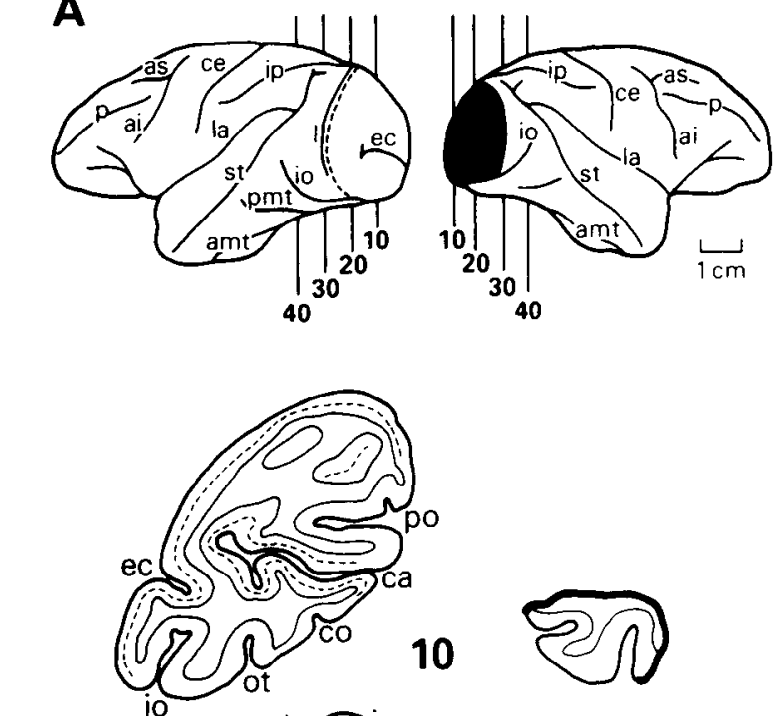

10
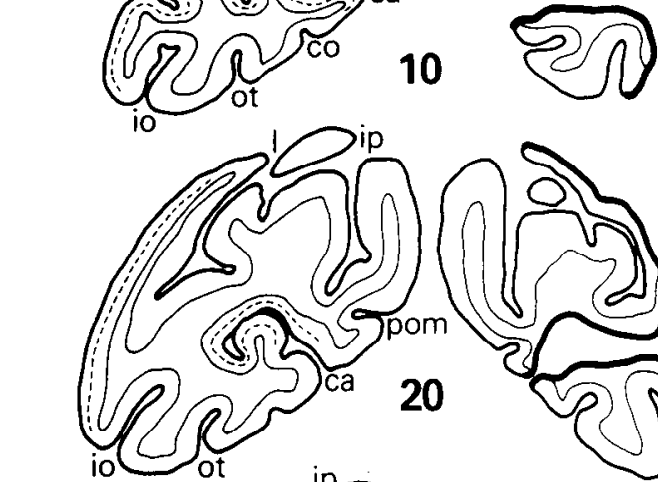

20

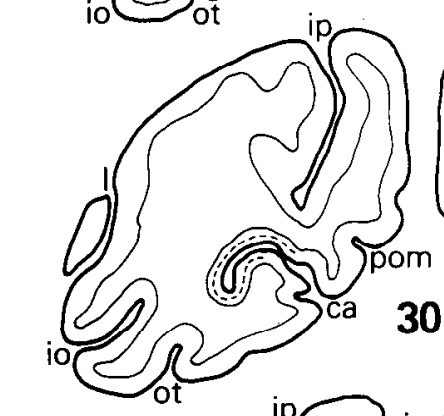

30
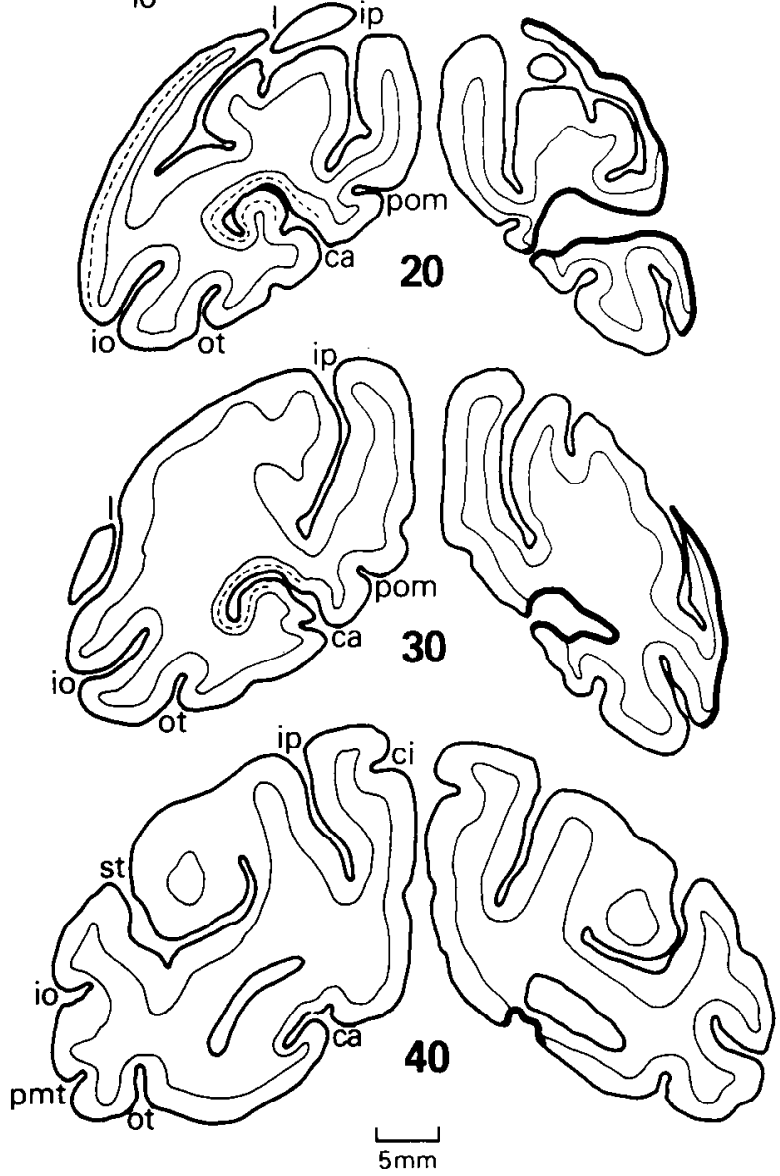

B
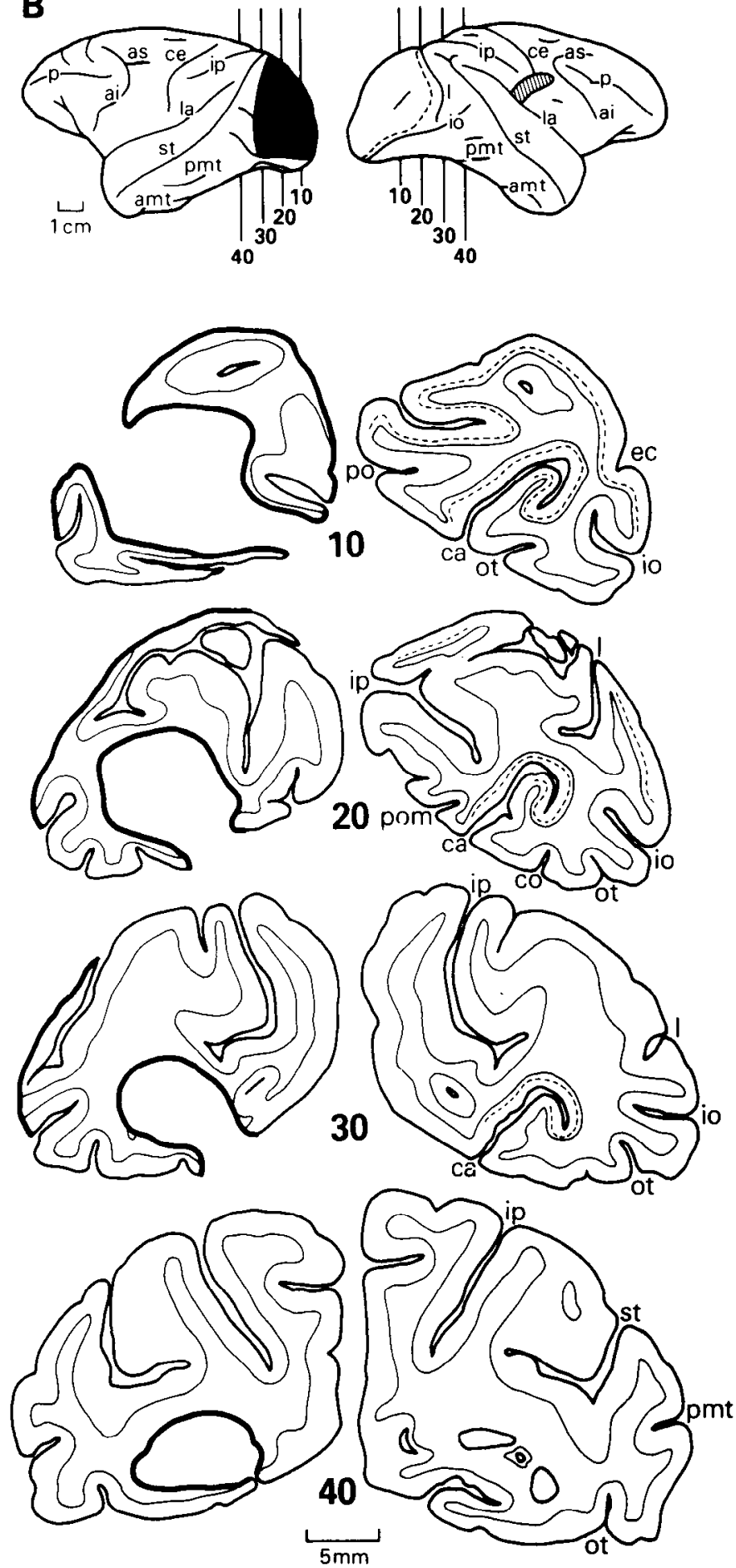

Figure 1. Unilateral lesion of striate cortex for the 2 monkeys with eyecoil implants, M19 $(A)$ and M23 $(B)$. The lesion is indicated by blackened area on reconstruction of lateral view of the brain (top) and by heavy black lines on tracings of individual cross sections (below). Dashed lines on drawings of the intact hemisphere indicate the border of striate cortex on lateral view and the extent of striate cortex on cross sections. Note that in one of the monkeys, M23, there was a small lesion in the sensorimotor cortex (hatch on lateral view) contralateral to the striate lesion. The former lesion underlay one of the monkey's restraining bolts and was probably a vascular lesion that occurred at the time of bolt implantation. We did not use any tests to assess sensorimotor function, but the lesion had no apparent effect on either visual or oculomotor performance. Abbreviations: $a i$, inferior limb of arcuate sulcus; $a m t$, anterior middle temporal sulcus; $a s$, superior limb of arcuate sulcus; ca, calcarine fissure; $c e$, central sulcus; $c i$, cingulate sulcus; $c o$, collateral sulcus; $e c$, external calcarine sulcus; $i o$, inferior occipital sulcus; $i p$, intraparietal sulcus; $l$, lunate sulcus; $l a$, lateral sulcus; ot, occipitotemporal sulcus; $p$, principal sulcus; $p m t$, posterior middle temporal sulcus; po, parieto-occipital sulcus; $p o m$, medial parieto-occipital sulcus; st, superior temporal sulcus. 

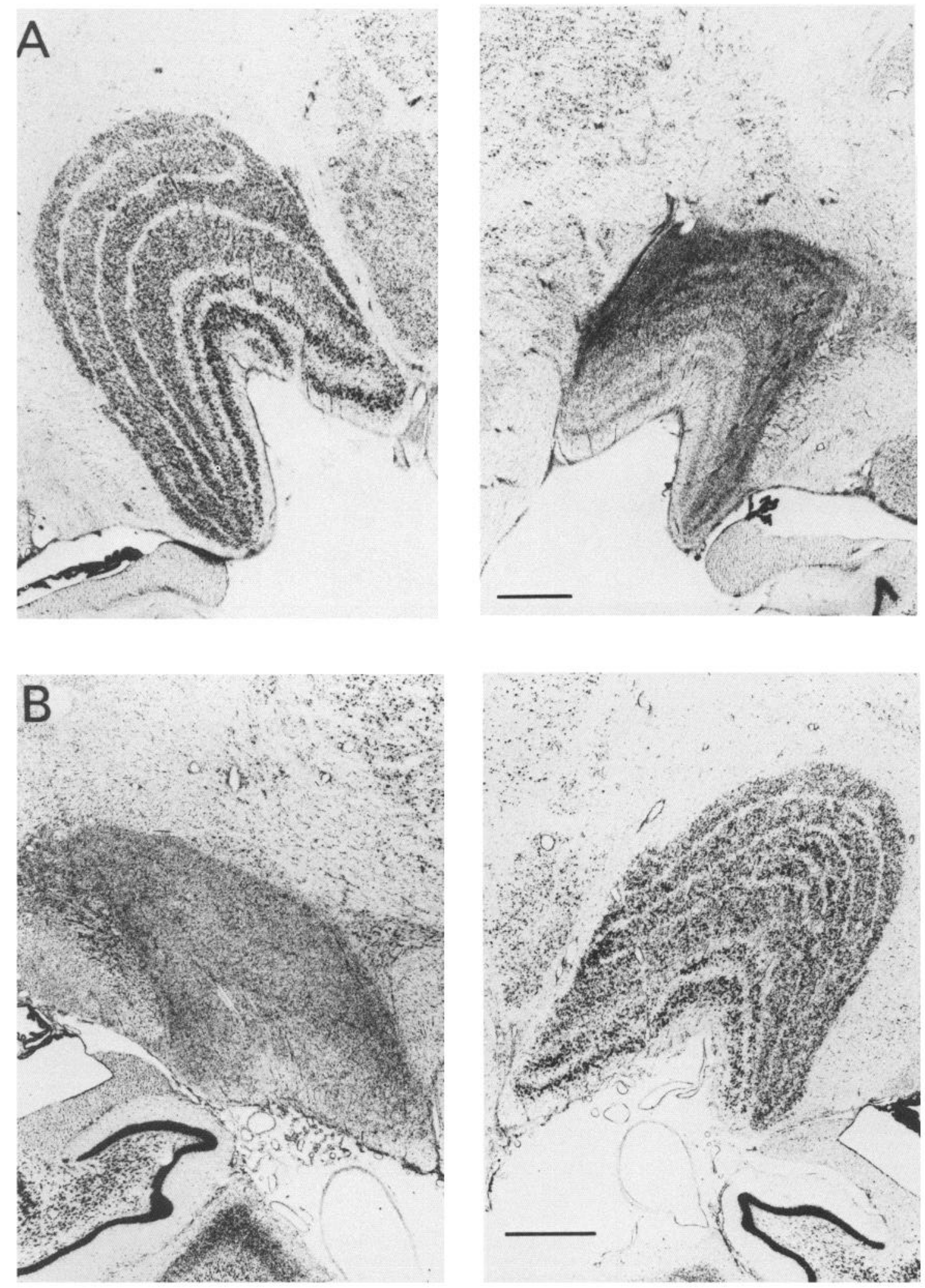

Figure 2. Photomicrographs of representative cross sections through the dorsal lateral geniculate nucleus (dLGN) of the 2 monkeys, M19 (A) and M23 $(B)$, whose lesions are shown in Figure 1. In both monkeys, there was virtually total retrograde degeneration of the dLGN ipsilateral to the striate removal, indicating the completeness of the removal. High-power photomicrographs of the degenerated dLGN of M19 (top right) are shown in Figure 3. Scale markers, $1 \mathrm{~mm}$. 


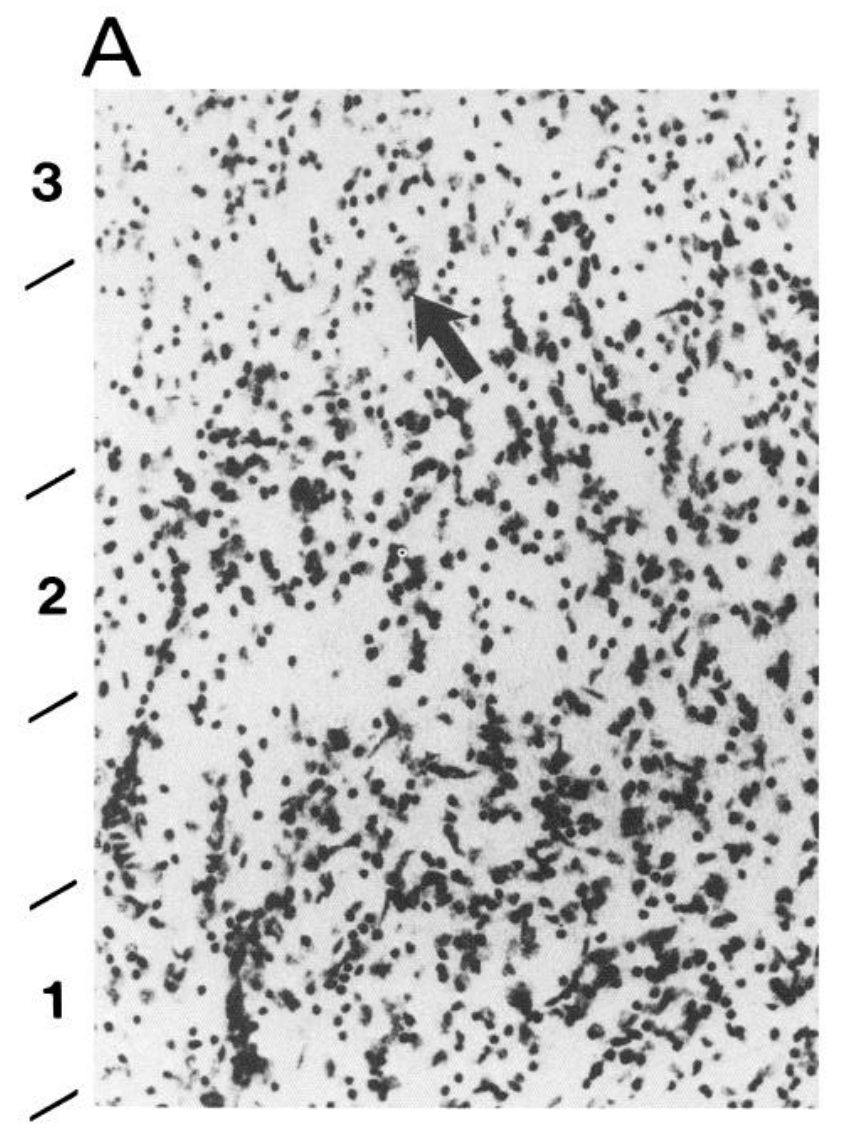

\section{B}

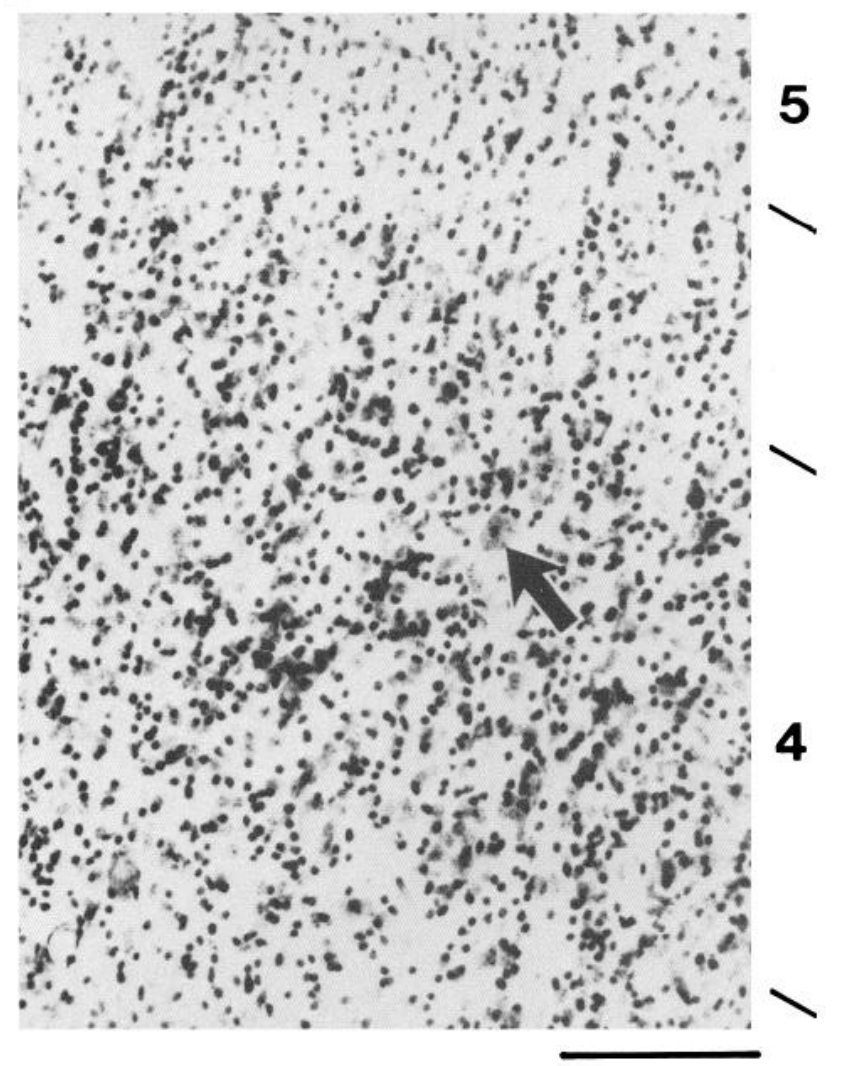

Figure 3. High-power photomicrographs of the degenerated dLGN of M19, which show that its laminar appearance is attributable to glial cells and not to neurons. Arrows indicate the only 2 neurons in the field, one within an interlaminar zone (between magnocellular layer 2 and parvocellular layer 3 in $A$ ) and another within a parvocellular lamina (layer 4 in $B$ ). We have observed a wide variation in the extent to which a degenerated $\mathrm{dLGN}$ retains such a laminar appearance following striate removal, but the reason for this variation is unknown at present. Scale marker, $100 \mu \mathrm{m}$.

correction only occurred during saccades, because the velocity was determined in real time in units of $5^{\prime}$ of arc every $2 \mathrm{msec}$, and multiplication was performed by integer-shifting. Thus, only if the eye velocity was greater than $333 \% \mathrm{sec}$ was the correction factor nonzero. Because comparison of the monkey's eye position with the actual mirror position feedback signal revealed a small amount of retinal slip during saccades, we have referred to the technique as quasistabilization to emphasize that the image was probably never as well stabilized as it would have been by a mirror fixed to the eye or by an afterimage. Because the stabilization resulted in the monkey's eye inevitably remaining in the window, stabilization trials were always randomly intermixed with nonstabilized pursuit or fixation trials to maintain the quality of the monkey's performance.

4. Initiation of pursuit by a parafoveally quasistabilized target. Each trial began with a fixation. At an unpredictable time, the target was stepped $1^{\circ}-5^{\circ}$ away from the fovea, and from then on its position was quasistabilized by the same method used in the previous paradigm. These trials were not intermixed with nonstabilized pursuit or fixation trials.

5. Pursuit of vertical target movement combined with horizontal target stabilization. These trials began with fixation. After an unpredictable time interval, the target was stepped horizontally $1^{\circ}-5^{\circ}$ and the horizontal component of target position was then quasistabilized. At the same time, the vertical component of target position assumed a sinusoidally varied velocity without stabilization.

For each of the above paradigms, each monkey served as its own control, since we were able to compare eye movements evoked by visual stimuli presented in the field contralateral to the striate lesion with eye movements evoked by the same stimuli presented in the field ipsilateral to the lesion.

Data analysis. Eye position, stimulus position (either the signal sent to the mirror galvanometer or the signal from the mirror position monitor), and a behavioral event trace were sampled at a rate of $1 \mathrm{kHz}$. These data were stored on-line by the laboratory computer and then transferred to a UNIX system for off-line analysis. Raw eye-movement data were digitally filtered and differentiated using finite impulse response (FIR) filters (Rabiner and Gold, 1975). All numerical values were computed from these filtered data. For analysis of step-ramp trials, the computer displayed each trial on a monitor. Our analysis software placed cursor marks at the beginning and end of each saccade and at the target step. For each trial, the computer's placement of cursors was verified by eye to insure that the cursor was placed at the velocity minimum after the saccade for ramps in the same direction as the saccade, or at the zero crossing point of the velocity signal for ramps in the direction opposite to the saccade. For trials in which the saccade had obvious dynamic overshoot, saccadic amplitude was taken as the distance from the point of saccadic initiation to the end of the overshoot. Saccadic error was defined as the distance between the eye and target positions at the end of the saccade. By convention, overshoots were given a positive value, and undershoots were given a negative value. Postsaccadic pursuit velocity was defined as the velocity value at the cursor marking the end of the saccade. Postsaccadic pursuit gain was the ratio of postsaccadic pursuit eye velocity to ramp velocity. Since the velocity traces included in the figures were calculated by filtering eye position with a digital filter, velocities at the very beginning of the traces are indeterminate. In addition, the FIR filter broadened the velocity trace without inducing a temporal shift.

The saccade data illustrated for monkey M23 were based on 689 trials from a single day during which ramp speed was kept constant at $30 \%$ sec and step amplitude varied randomly in $5^{\circ}$ steps from $5^{\circ}$ to $20^{\circ}$. Step direction, step amplitude, and ramp direction were mixed in an unpredictable manner. This enabled us to analyze quantitatively the data 
from a large number of trials that did not have inconsistencies resulting from day-to-day changes in eye-position calibration or in the behavioral performance of the monkey.

\section{Results}

Preliminary observations of the oculomotor capacity of monkeys with unilateral striate lesions were made in the 2 monkeys with EOG electrodes. It was apparent from a qualitative study of their saccadic performance that the monkeys were quite accurate in making saccades to stationary targets in the field contralateral to their striate lesion, but had difficulty in making saccades to moving targets in that hemifield. It was also apparent that their foveal pursuit was normal. With the development of search coil methods and more quantitative methods for eyemovement analysis, it became appropriate to reexamine the oculomotor capacity of monkeys with unilateral striate lesions. The quantitative data reported here are from the 2 monkeys with the implanted eye coils. They provide quantitative support and corroborative detail for the qualitative observations made first in the monkeys with EOG electrodes.

\section{Saccadic eye movements}

Saccades to stationary targets. Monkeys with striate lesions made fairly accurate saccades to stimuli stepped into the field contralateral to the lesion as long as the target remained stationary after the step. Figure 4 shows the distribution of saccadic errors for all the step-only trials recorded on a single day for monkey M23. This monkey showed a small but consistent tendency to overshoot stimuli stepped into the field contralateral to the lesion, and the mean error for these trials was significantly different from zero $(p<0.0001)$. This overshoot appeared to be an intentional effort by the monkey to put the stimulus in the intact hemifield, and the monkey did not correct this error. The mean error for saccades by M23 to stimuli stepped into the field ipsilateral to the lesion was not significantly different from zero. For M19 there was no significant difference between the mean saccadic errors in the 2 hemifields, but this monkey tended to overshoot the target by $1 / 2^{\circ}$ in both hemifields. Table 1 lists

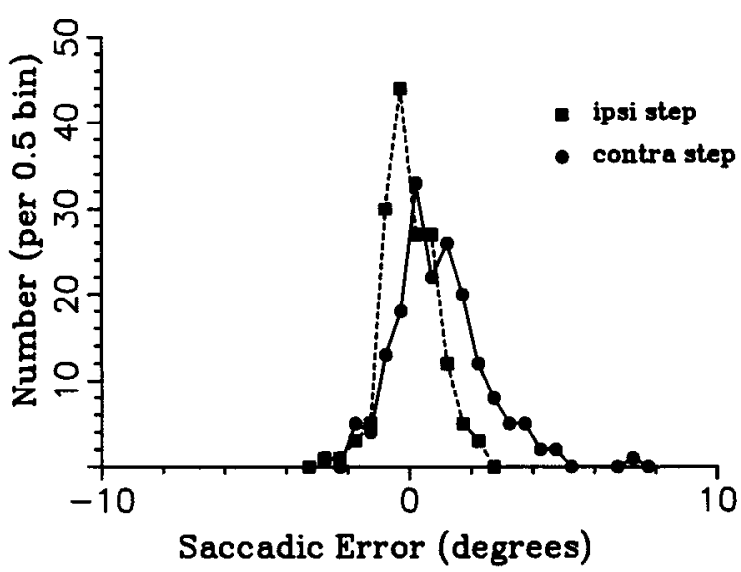

Figure 4. Error distributions for saccades to stationary targets. Squares and dashed line outline the distribution of saccadic errors for saccades to targets presented in the field ipsilateral to the striate lesion. Circles and solid line outline the distribution of saccadic errors for saccades to targets presented in the field contralateral to the striate lesion. Values less than 0 signify undershoots of the target, and values greater than 0 signify overshoots. Step amplitude varied randomly in $5^{\circ}$ increments between $5^{\circ}$ and $20^{\circ}$. The mean error for saccades into the field ipsilateral to the striate lesion was $0.00^{\circ}(\mathrm{SD}=0.82, \mathrm{SEM}=0.07, n=158)$. The mean error for saccades into the field contralateral to the striate lesion was $0.95^{\circ}(\mathrm{SD}=1.45, \mathrm{SEM}=0.11, n=176)$. Monkey M23, left striate lesion.

means, standard deviations, and standard errors for the saccadic errors made by M23 and shown in Figure 4, as well as for a set of experiments in monkey M19 during which all steps were $10^{\circ}$ in magnitude. Although the saccadic errors were, on the whole, surprisingly small, the consistently larger standard deviations for saccades into the field contralateral to the lesion suggest that the monkeys did have a slight difficulty making saccades to stationary targets.

Saccades to step-ramp targets. Saccades to step-ramp targets were accurate only into the field ipsilateral to the lesion. Figure

Table 1. Mean saccadic errors for monkeys M19 and M23

\begin{tabular}{|c|c|c|c|c|c|c|}
\hline & Task & Error & SD & SEM & $n$ & $\begin{array}{l}\text { Signifi- } \\
\text { cance }\end{array}$ \\
\hline \multicolumn{7}{|c|}{ Step ipsilateral to striate lesion } \\
\hline \multirow[t]{3}{*}{ Monkey M19 } & No ramp & 0.51 & 0.43 & 0.11 & 15 & $p<0.0002$ \\
\hline & Ramp-away & 0.51 & 0.59 & 0.13 & 18 & n.s. \\
\hline & Ramp-back & -0.02 & 0.59 & 0.13 & 22 & $p<0.02$ \\
\hline \multirow[t]{3}{*}{ Monkey M23 } & No ramp & 0.00 & 0.82 & 0.07 & 158 & n.s. \\
\hline & Ramp-away & -0.04 & 0.94 & 0.08 & 124 & n.s. \\
\hline & Ramp-back & -0.49 & 0.65 & 0.10 & 43 & $p<0.0002$ \\
\hline \multicolumn{7}{|c|}{ Step contralateral to striate lesion } \\
\hline \multirow[t]{3}{*}{ Monkey M19 } & No ramp & 0.54 & 1.67 & 0.39 & 18 & n.s. \\
\hline & Ramp-away & -2.81 & 1.27 & 0.23 & 29 & $p<0.0001$ \\
\hline & Ramp-back & 3.59 & 1.23 & 0.03 & 16 & $p<0.0001$ \\
\hline \multirow[t]{3}{*}{ Monkey M23 } & No ramp & 0.95 & 1.45 & 0.11 & 176 & $p<0.0001$ \\
\hline & Ramp-away & -3.89 & 1.52 & 0.15 & 101 & $p<0.0001$ \\
\hline & Ramp-back & 5.32 & 1.82 & 0.20 & 87 & $p<0.0001$ \\
\hline
\end{tabular}

Significance values are for comparison of no-ramp theans to zero, and of ramp-away and ramp-back means to the mean for the no-ramp condition. Positive error values represent overshoots of the target, and negative error values represent undershoots. For $\mathrm{M} 19$, all steps were $10^{\circ}$, and all ramps had a speed of $15 \mathrm{deg} / \mathrm{sec}$. For M23, step amplitude varied randomly in $5^{\circ}$ increments between $5^{\circ}$ and $20^{\circ}$, and ramp speed was kept constant at $30 \mathrm{deg} / \mathrm{sec}$. $n=$ Number of trials. Significance in this and subsequent tables ascertained by 1 -tailed Student's $t$ test. 


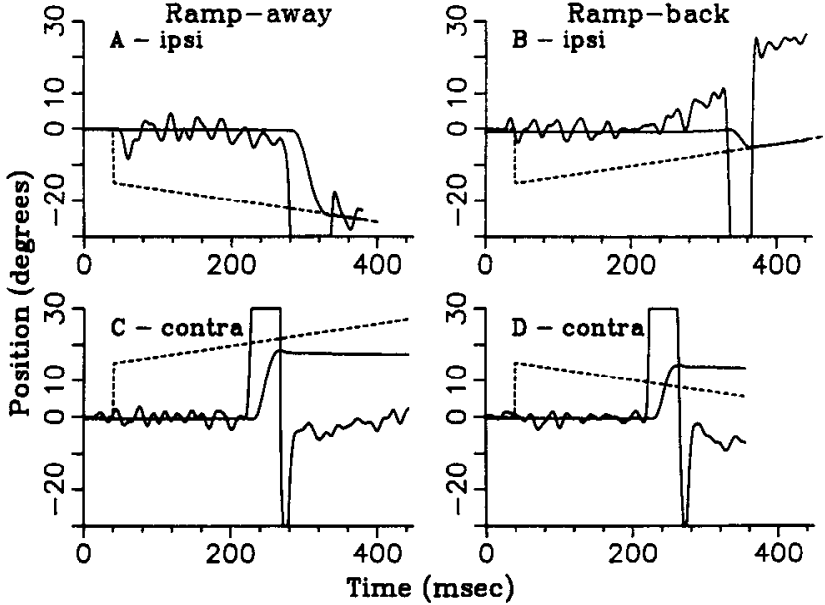

Figure 5. Tracking of step-ramp stimuli moving horizontally by monkey with left striate ablation (M23). Horizontal components of eye position and velocity are represented by solid lines. The velocity trace can easily be distinguished from the position trace by its higher noise level and the fact that eye velocity during the saccade must be clipped. Horizontal components of target positions are represented by dashed lines. The target position trace is extended for $20 \mathrm{msec}$ in $A$ and $B$. The velocity calibration is identical in $\mathrm{deg} / \mathrm{sec}$ to the position calibration. In this and subsequent figures, eye position is displayed, not as single data points, but as a line synthesized by a linear interpolation between data points. Movement to the right is shown as up in the figure, and movement to the left is down. Sample rate, $1 \mathrm{kHz}$. $A$, Stimulus stepped into the field ipsilateral to the lesion with ramp directed away from the center of gaze. $B$, Stimulus stepped into the field ipsilateral to the lesion with ramp directed back towards the center of gaze. $C$, Stimulus stepped into the field contralateral to the lesion with ramp away from the center of gaze. $D$, Stimulus stepped into the field contralateral to the lesion with ramp back towards the center of gaze.

5 shows single examples of saccades to horizontal step-ramp targets for monkey M19. The saccades were accurate for steps into the field ipsilateral to the lesion (Fig. 5, $A, B$ ), but showed significant undershoots for ramp-away trials (Fig. $5 C$ ) and overshoots for ramp-back trials (Fig. 5D) into the field contralateral to the lesion. Figure 6 shows the distribution of saccadic errors for a series of trials by monkey M23. When the stimulus stepped into the field ipsilateral to the lesion (Fig. 6A), saccades to rampaway and ramp-back targets were accurate. By contrast, for ramp trials with steps into the field contralateral to the lesion (Fig. $6 B)$, the error was large and significantly different from the error in the no-ramp condition. There werc significant undershoots for ramp-away trials and significant overshoots for ramp-back trials. In each case the error was greater for ramp-back trials than for ramp-away trials. This may not reflect an intrinsic difference in the velocity processing for approaching and receding targets. Both monkeys tended to overshoot stationary targets in the field contralateral to the lesion. If the amount of overshoot to stationary targets is added to the mean error for contralateral ramp-away trials and subtracted from the mean error for rampback trials, the differences between absolute errors for rampaway and ramp-back trials are no longer significant. In neither monkey was there a significant difference between mean errors in ramp-away trials and in no-ramp trials for stimuli stepped into the field ipsilateral to the lesion. However, there was a slight difference in this field between mean errors for ramp-back and no-ramp trials. In each monkey the difference was less than $0.5^{\circ}$, and in one monkey (M19) the ramp-back trials were the more accurate. The data from monkey M23 shown in Figure 6,

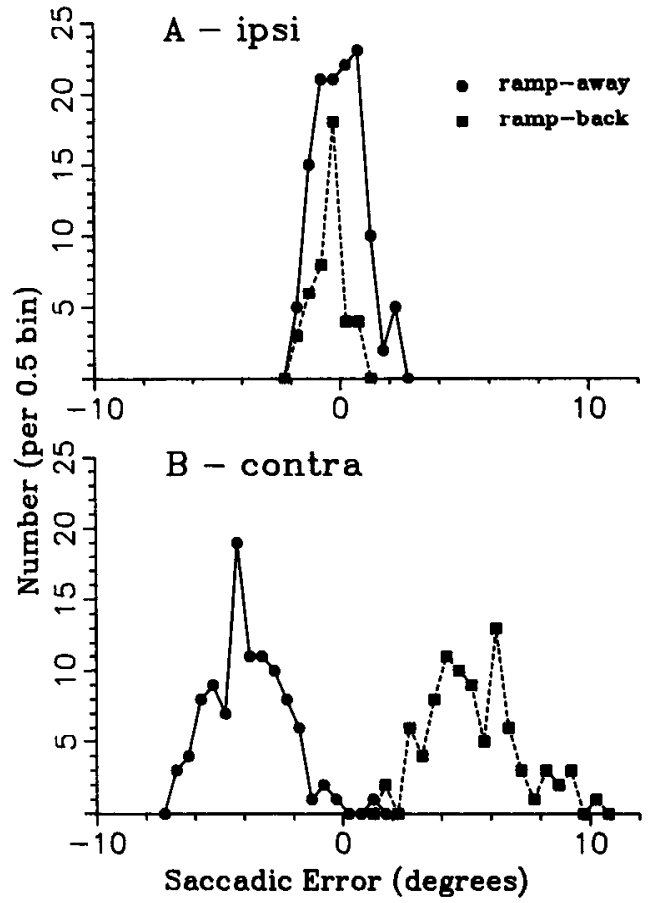

Figure 6. Error distributions for saccades to step-ramp targets. Circles and solid line outline the distribution of saccadic errors for saccades to targets stcpped and then ramped away from the central fixation point. Squares and dashed line outline the distribution of saccadic errors for saccades to targets stepped and then ramped back towards the central fixation point. Values less than 0 signify undershoots of the target, and values greater than 0 signify overshoots. Step amplitude varied randomly in $5^{\circ}$ increments between $5^{\circ}$ and $20^{\circ}$, and ramp speed was kept constant at $30 \% \mathrm{sec}$. $A$, Error distributions for targets presented in the field ipsilateral to the striate lesion. The mean error for ramp-away trials was $-0.04^{\circ}(\mathrm{SD}=0.94, \mathrm{SEM}=0.08, n=124)$, and the mean error for ramp-back trials was $-0.49^{\circ}(\mathrm{SD}=0.65, \mathrm{SEM}=0.10, n=43)$. $B$, Error distributions for targets presented in the field contralateral to the striate lesion. The mean error for ramp-away trials was $-3.89^{\circ}(\mathrm{SD}=1.52$, $\mathrm{SEM}=0.15, n=101$ ), and the mean error for ramp-back trials was $5.32^{\circ}(\mathrm{SD}=1.82, \mathrm{SEM}=0.20, n=87)$. Monkey M23.

as well as the data from monkey M19, are summarized in Table 1 .

Relationship of ramp direction to saccadic latency. Both monkeys varied the latency of their saccades to targets in the field ipsilateral to the lesion according to the presence or absence, as well as the direction, of stimulus movement. When the stimulus moved back towards the center of gaze, the monkeys delayed the initiation of saccades relative to their saccadic latency for stimuli moving away. When the target was stationary in the field ipsilateral to the lesion, monkey M23 made saccades with latencies intermediate between those for saccades to stimuli moving towards and those moving away from the center of gaze, and M19 made saccades with latencies that were shorter than those to moving targets. In contrast, there was little variability in latency in either monkey when the stimulus was stepped into the field contralateral to the lesion. Figure 7 shows the distribution of latencies for saccades recorded from monkey M23. Note that there were 3 different latency distributions for the 3 stimulus movement conditions in the field ipsilateral to the striate lesion (Fig. 7A). By contrast, when the stimulus stepped into the field contralateral to the lesion, the 3 latency distributions were superimposed (Fig. $7 B$ ). Data from both monkeys are summarized in Table 2 . For monkey M23, the mean latency 
for saccades into the affected field was shorter than that for saccades into the intact ileld. For monkey M19, this difference was reversed.

This latency effect was not due to the isolated effect of saccade amplitude on saccade latency. For example, for $\mathrm{M} 23$, in the field contralateral to the lesion, latency varied as a function of amplitude, with the slope of $-0.96 \mathrm{msec} / \mathrm{deg}(r=-0.18, p<$ 0.001 , standard error of slope, 0.24 ). The mean amplitude difference between ramp-back trials and ramp-away trials was $13^{\circ}$, which could account for a $13 \mathrm{msec}$ latency difference but not for the observed $92 \mathrm{msec}$ latency difference.

Relationships of latency to performance. Since saccades to stationary targets were accurate in both fields, it was clear that our monkeys were not blind in the field contralateral to the lesion. There were at least 2 possible explanations for the striking inaccuracy of their saccades to moving targets. The first was that the monkey could process the transient visual signal of the step, but not that of the slowly moving stimulus; that is, the monkey was blind to all aspects of the moving target. The second was that the monkey could detect the position of a slowly moving target but not its velocity; that is, it was blind to the target's velocity, but not to its position. In the latter case, the monkey might view the moving target as a continuous series of images of static target position. In order to choose between these alternatives, we examined the relationship of saccadic latency to saccadic error and amplitude.

If the target were visible only at the initial stepped position and not visible when it moved, then saccadic error should increase with increasing saccadic latency because the distance the target moved between target step and saccadic termination increased with increasing latency. If, however, the saccade were made to the position of the moving target, then there should be no correlation between saccadic error and latency. Figure 8 and Table 3 show that latency and error were in fact uncorrelated for saccades to moving targets in either hemifield. Note that 2 populations of saccadic error, one for ramp-back trials and one for ramp-away trials, are apparent in the scatter diagrams for the field contralateral to, but not for the field ipsilateral to the lesion (compare with Fig. 6).

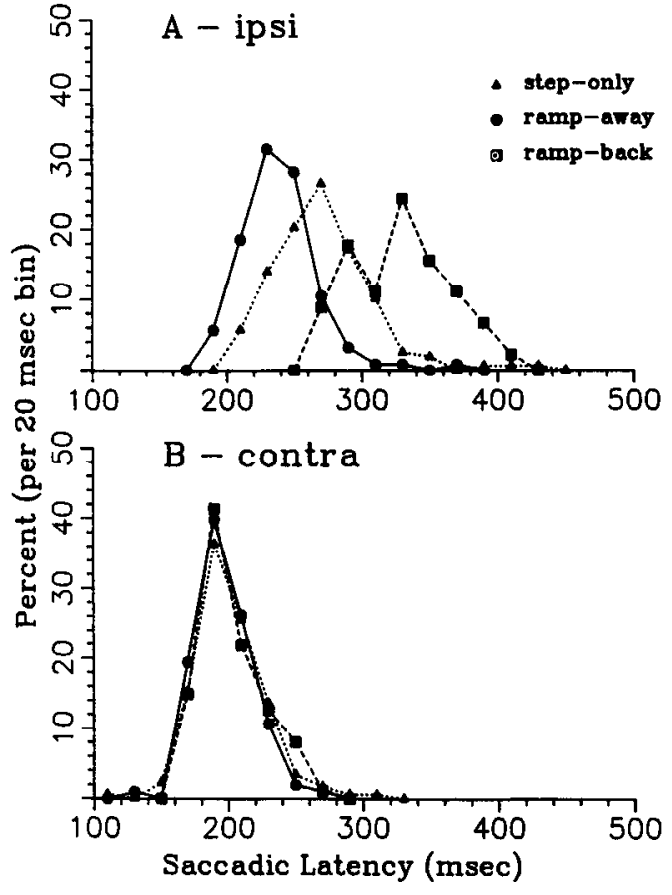

Figure 7. Effect of ramp direction upon saccadic latency. Percentage distributions of saccadic latencies for step-only (triangles), ramp-away (circles), and ramp-back (squares) trials. $A$. Distribution for targets presented in the field ipsilateral to the striate lesion. Mean latencies: steponly, 269.7 msec; ramp-away, $237.0 \mathrm{msec}$; ramp-back, $330.0 \mathrm{msec}$. $B$, Distribution for targets presented in the field contralateral to the striate lesion. Mean latencies: step-only, $199.8 \mathrm{msec}$; ramp-away, $196.7 \mathrm{msec}$ ramp-back, $202.0 \mathrm{msec}$. Monkey M23.

The lack of correlation between saccadic error and latency implies that the monkey not only detected the moving target but was able to supply the saccadic system with a measure of its changing position over time. Assuming that this was the case, then, for increasing saccadic latency, a portion of saccadic length should reflect the ongoing change in position of the target due to ramp velocity. To determine the amount of saccadic ampli-

Table 2. Mean saccadic latencies for monkeys M19 and M23

\begin{tabular}{|c|c|c|c|c|c|c|}
\hline & Task & Latency & SD & SEM & $n$ & $\begin{array}{l}\text { Signifi- } \\
\text { cance }\end{array}$ \\
\hline \multicolumn{7}{|c|}{ Step ipsilateral to striate lesion } \\
\hline \multirow[t]{3}{*}{ Monkey M19 } & No ramp & 187.6 & 17.0 & 4.4 & 15 & $p<0.0001$ \\
\hline & Ramp-away & 238.0 & 32.9 & 7.7 & 18 & \\
\hline & Ramp-back & 264.0 & 50.1 & 10.7 & 22 & $p<0.03$ \\
\hline \multirow[t]{3}{*}{ Monkey M23 } & No ramp & 269.7 & 36.2 & 2.9 & 158 & $p<0.0001$ \\
\hline & Ramp-away & 237.0 & 27.2 & 2.4 & 124 & \\
\hline & Ramp-back & 330.0 & 36.0 & 5.5 & 43 & $p<0.0001$ \\
\hline \multicolumn{7}{|c|}{ Step contralateral to striate lesion } \\
\hline \multirow[t]{3}{*}{ Monkey M19 } & No ramp & 251.0 & 43.2 & 9.9 & 18 & n.s. \\
\hline & Ramp-away & 260.6 & 34.4 & 6.5 & 29 & \\
\hline & Ramp-back & 263.9 & 39.7 & 9.9 & 16 & n.s. \\
\hline \multirow[t]{3}{*}{ Monkey M23 } & No ramp & 199.8 & 26.0 & 2.0 & 176 & n.s. \\
\hline & Ramp-away & 196.7 & 20.0 & 2.0 & 101 & \\
\hline & Ramp-back & 202.0 & 23.3 & 2.5 & 87 & n.s. \\
\hline
\end{tabular}

Significance values for no-ramp conditions represent a comparison to the closer of the means obtained in either rampaway or ramp-back conditions. Significance values for ramp-back conditions represent a comparison to the means obtained in the ramp-away condition. 
Figure 8. Relationship of saccadic error to latency. Circles, ramp-away trials; squares, ramp-back trials. Distribution of saccadic error versus saccadic latency $(A)$ for targets presented in the field ipsilateral to the striate lesion, and $(B)$ for targets presented in the field contralateral to the striate lesion. There was no correlation between error and latency for any step-ramp combination. Monkey M23.

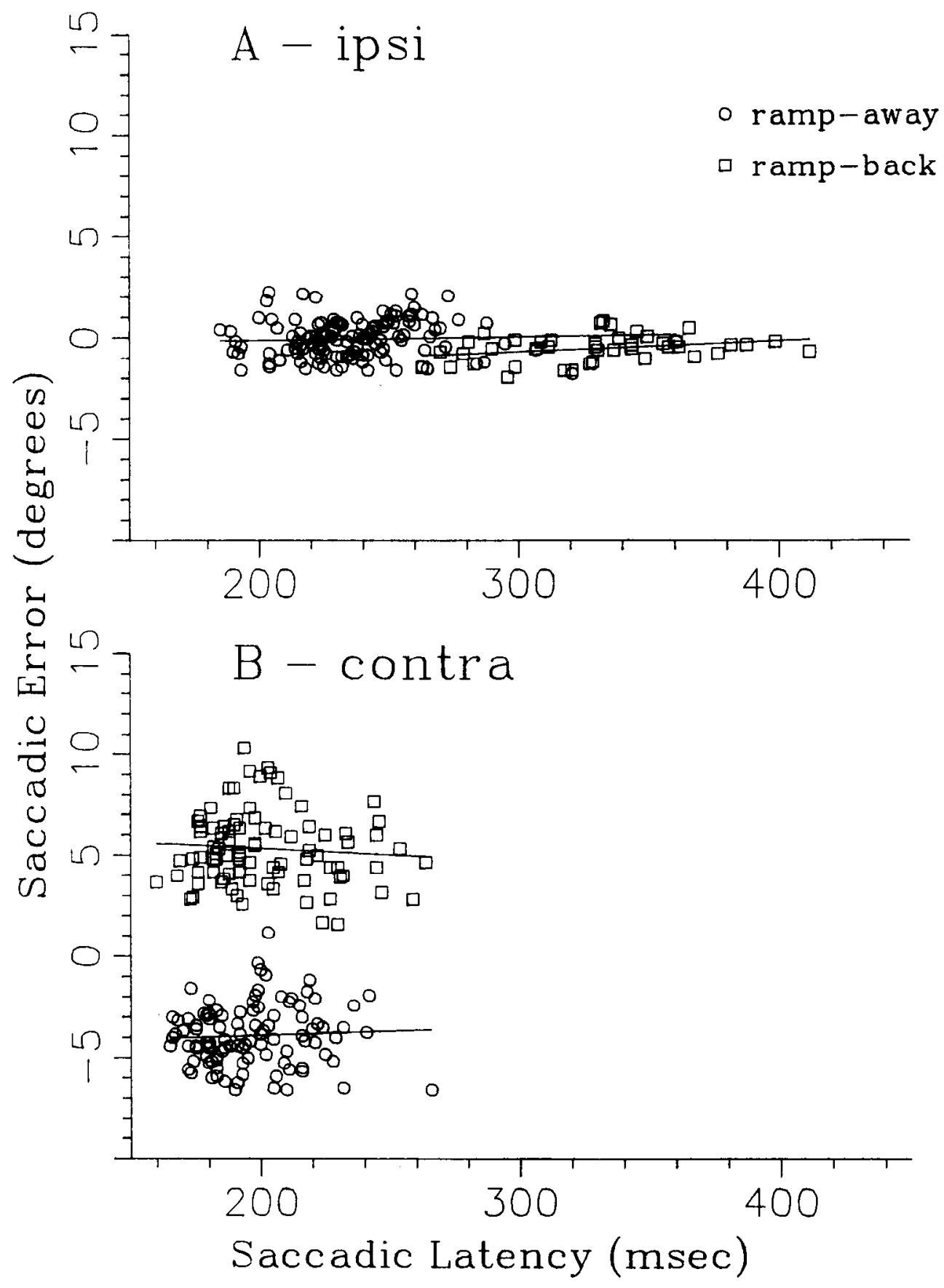

tude attributable to ramp movement, we subtracted target step size from saccadic amplitude for each trial, obtaining a value designated "adjusted saccadic amplitude." Because the step size was removed from the measure, it allowed us to group together saccades to targets of different step amplitudes but with the same ramp velocity. If the saccade were a response to the step alone, that is, if there were no saccadic component attributable to target movement after the step, then the adjusted saccadic amplitude should be zero. However, this was not the case for stimuli presented in either the left or right visual field. Figure 9 shows scatter diagrams of adjusted saccadic amplitude versus latency for steps into the field ipsilateral (Fig. 9A) and contralateral (Fig. $9 B)$ to the lesion. Saccades with target steps of $5^{\circ}, 10^{\circ}, 15^{\circ}$, and $20^{\circ}$ were included in the sample. There was a significant correlation (Table 3 ) for all directions of step and ramp, and the slopes of the regression lines approximated the ramp velocity of $30 \% \mathrm{sec}$. For trials with stimuli presented in the field ipsilateral to the striate lesion, the presaccadic pursuit velocity decreased the slope of adjusted saccadic amplitude versus latency, especially for ramp-back trials, which had the longest saccadic latency. Thus, the data for M23 establish that the monkey's residual visual capability enabled it to determine where the moving target was in space.

\section{Smooth pursuit eye movements}

Smooth pursuit to moving targets. All monkeys were capable of foveal smooth pursuit movements in all directions for a broad range of velocities. Figure 10 shows the horizontal eye position recorded while monkey M19 tracked a stimulus moving back and forth in the horizontal dimension with velocity varied at 2 


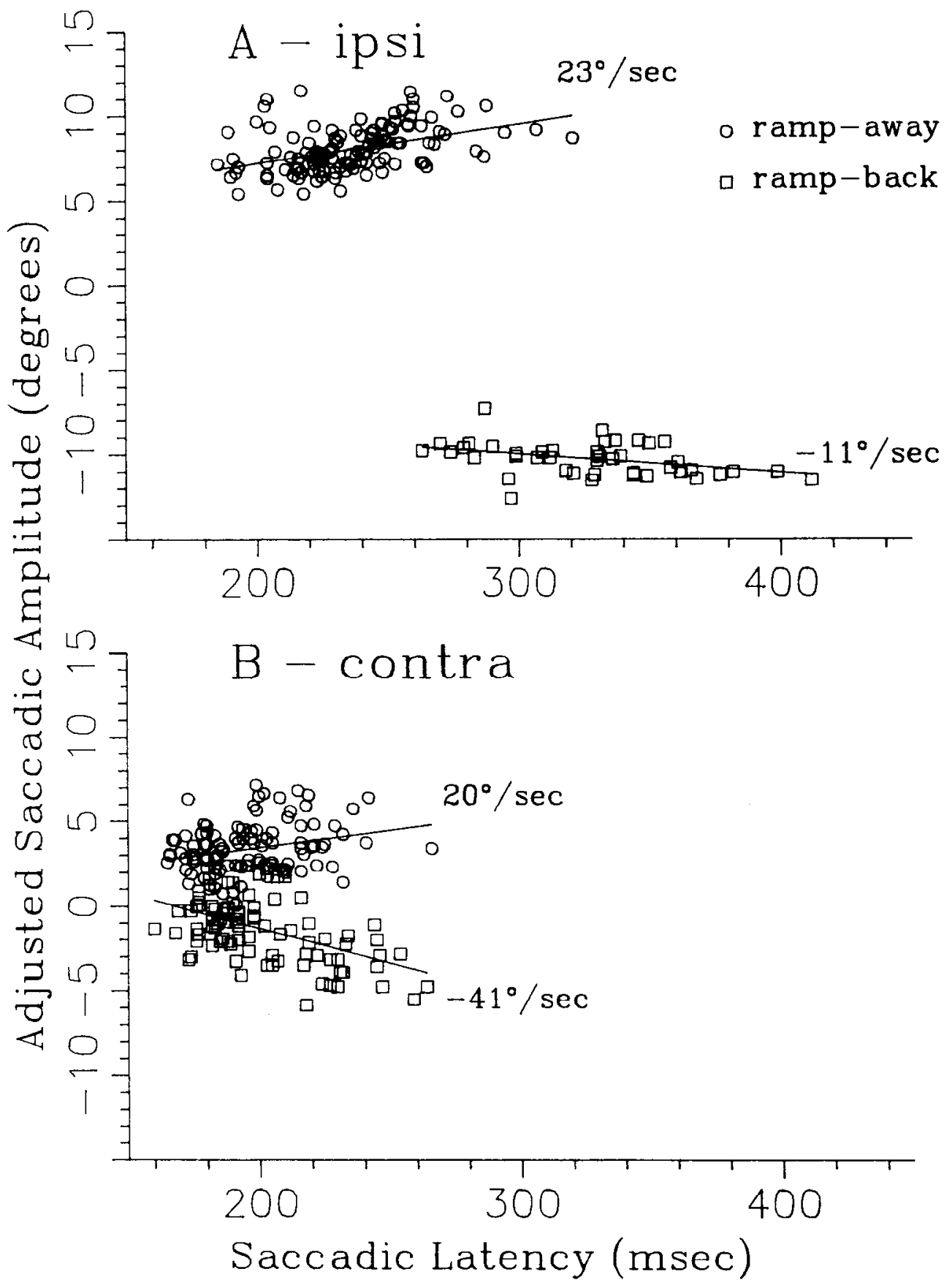

Figure 9. The rclationship of adjustcd saccadic amplitude to saccade latency. Circles, ramp-away trials. Squares, ramp-back trials. Adjusted saccadic amplitude versus saccadic latency for $(A)$ targets presented in the field ipsilateral to the striate lesion, and $(B)$ targets presented in the field contralateral to the striate lesion. The correlation between adjusted saccadic amplitude and latency was highly significant in each case. The relatively low slope for ipsilateral step-ramp-back trials is attributable to the development of an appreciable presaccadic pursuit movement in the direction of the ramp, thereby effectively increasing saccadic amplitude. Monkey M23. different frequencies. Note that the monkey developed epochs of adequate smooth pursuit in both directions at both frequencies. When we used step-ramp stimuli to assess the ability of the monkeys to generate smooth pursuit movements to stimuli moving in one hemifield, a marked deficit became apparent, which can be seen by inspecting the pursuit components of the step-ramp trials illustrated in Figure 5. Figure $5 \mathrm{~A}$ shows the pursuit of a stimulus stepped into the field ipsilateral to the lesion, and then moved away from the center of gaze. Figure $5 B$ shows the pursuit of a stimulus stepped into the intact field and then moved back towards the center of gaze. In each case the monkey pursued accurately by the time the saccade was over, as is shown by the superposition of eye- and stimulusposition traces. In the case in which the stimulus came back towards the center of gaze (Fig. $5 B$ ), the monkey developed a significant smooth pursuit velocity in the direction of stimulus movement before the saccade. This resulted in the paradoxical event of the eye moving away from the target prior to the saccade. These data imply that the monkey could use the target velocity in the field ipsilateral to the lesion to develop a smooth pursuit eye velocity. When the target stepped into the field contralateral to the lesion, there was no presaccadic development of eye velocity, and the postsaccadic velocity was far below that required, as can be seen in Figure $5, C$ and $D$.

The monkey's inability to use stimulus velocity in the field contralateral to the lesion was independent of the direction of stimulus motion. Figure 11 shows examples of monkey M19's attempt to pursue a peripheral stimulus moving downward. The stimulus was stepped obliquely upwards and then moved straight downwards. When the stimulus was stepped into the field ip- 


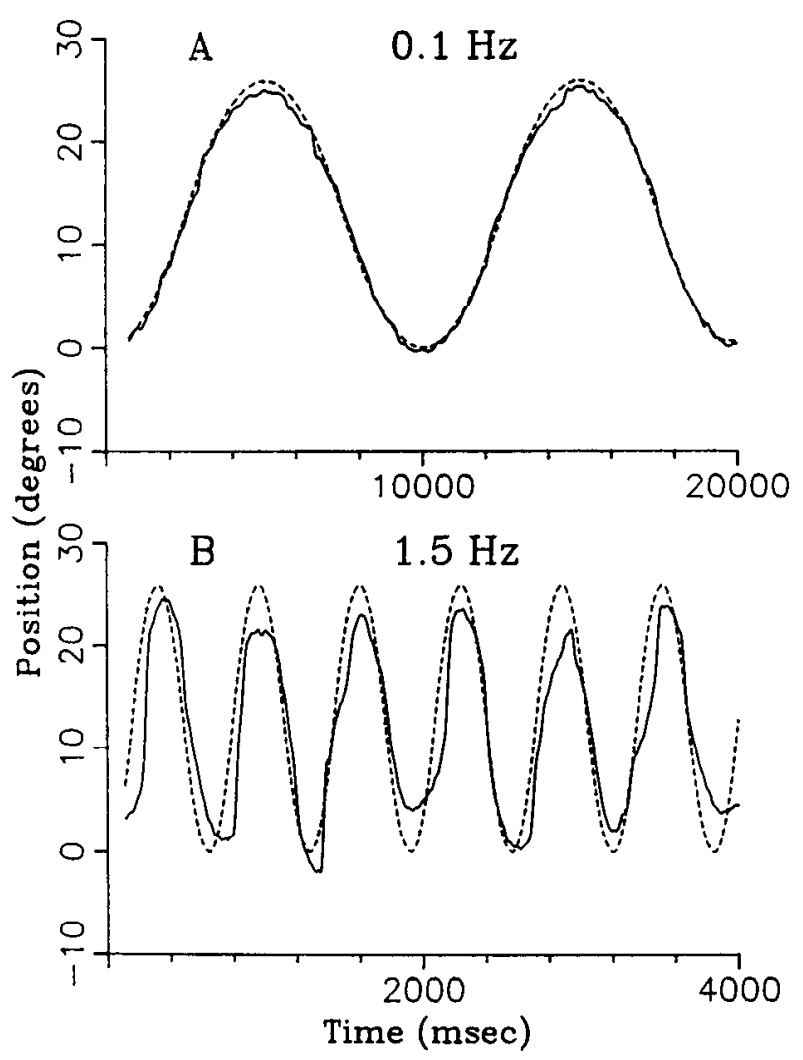

Figure 10. Pursuit of sinusoidal stimulus movement in monkey with unilateral right striate lesion (M19). A, Horizontal eye position (solid line) and target position (dashed line) while the monkey tracked a stimulus moving back and forth in the horizontal dimension with sinusoidally varied velocity. Movement amplitude was $25^{\circ}$ and frequency was $0.1 \mathrm{~Hz}$. $B$, Horizontal eye and target position while the monkey tracked a stimulus moving at $1.5 \mathrm{~Hz}$ over the same distance. Eye and target position were sampled at $250 \mathrm{~Hz}$.

silateral to the lesion (note that this example is taken from a monkey with a striate lesion in the hemisphere opposite to the one in the monkey shown in Fig. 5), the horizontal and vertical components of the saccade and the downward smooth pursuit were all accurate (Fig. 11A). When the stimulus was stepped into the field contralateral to the lesion (Fig. 11B), postsaccadic pursuit was impaired. Note that after the monkey made the first saccade, the target was moving downward in the foveal region represented in the intact hemisphere. The monkey's eye velocity matched target velocity by the end of the downward corrective saccade.

This inability to develop adequate smooth pursuit eye velocity from stimulus motion in the field contralateral to a striate lesion was consistent from monkey to monkey and from trial to trial. Figure 12 shows immediate postsaccadic pursuit gains (ratio of eye velocity to stimulus ramp velocity) calculated from series of step-ramp trials collected from both of the monkeys with eye coils. Gain distributions for each monkey for both horizontal and vertical pursuit are shown. For each monkey, both directions of pursuit in the field contralateral to the lesions had mean gains close to zero, significantly less than the mean gains for the same direction of pursuit in the intact field. Monkey M23 tended to end vertical saccades into the field contralateral to the lesion with an upward glissade, which was interpreted by the program as a significant pursuit velocity. Therefore, when the target also moved upward, the pursuit appeared substantial; but even when the target moved downward, the eye moved

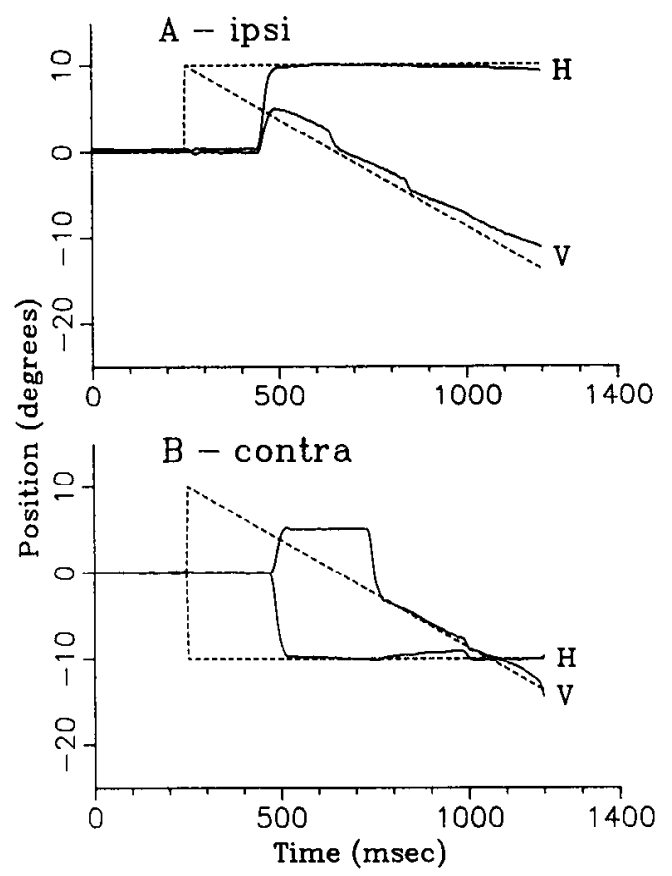

Figure 11. Downward pursuit of stimulus stepped into one hemifield by monkey with right striate ablation (M19). In each trace the vertical and horizontal components of eye position (solid lines) and stimulus position (dashed lines) are shown in the same coordinate system. The stimulus stepped obliquely upwards and then moved slowly downwards. The vertical component of stimulus movement included an upward step followed by a downward ramp, whereas the horizontal component included only a step into the field ipsilateral $(A)$ or contralateral $(B)$ to the lesion. Note that the horizontal component of the eye position after the saccade into either field was quite accurate, but that the vertical pursuit movement was adequate only when the stimulus was stepped into the field ipsilateral to the lesion $(A)$. Sample rate, $250 \mathrm{~Hz}$.

upward, and this resulted in a negative gain (Fig. 12D). The combination yielded a large standard deviation in the gain for vertical pursuit, but the mean was not significantly different from zero. Saccades into the field ipsilateral to the lesion ended with an appropriate eye velocity, and no negative gain was seen. Table 4 lists means, standard deviations, sample numbers, and significance levels for the examples shown. Thus, only the intact hemisphere supplied adequate stimulus-velocity information so that the eye could achieve a smooth pursuit velocity at the end of the saccade.

The monkeys could generate some smooth pursuit velocity, however, to stimuli limited to the field contralateral to the lesion. When they attempted to make a saccade to a target that stepped into the field contralateral to the lesion and then moved smoothly away, they usually undershot the target and had to make a corrective saccade. This corrective saccade was frequently followed by an eye velocity greater than that following the first saccade, even though the stimulus never crossed into the intact field. Such a trial is shown in Figure $13 A$ (monkey M23). Figure $13 B$ shows a scatter plot of velocities after the first (abscissa) and second (ordinate) saccades in all such trials as the sample illustrated above. In 31 trials in which the monkey made 2 horizontal saccades to the same stimulus, the mean velocity after the first saccade was $1.1 \% \mathrm{sec}(\mathrm{SD}=1.8, \mathrm{SEM}=0.3)$, and the mean velocity after the second saccade was $4.9^{\circ}(\mathrm{SD}=3.0$, SEM $=0.5)$. The means were significantly different, with $p<$ $0.0005(t=6.04, d f=60)$. There was no significant correlation between velocities after the first and second saccades. 
Table 3. Regressions of saccadic error versus latency, and adjusted saccadic amplitude versus latency

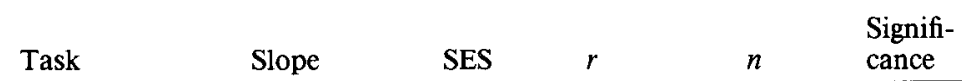

Regression, adjusted saccadic error versus latency

Step ipsilateral to striate lesion

$\begin{array}{rlrrrrr}\text { Monkey M23 } & \text { No ramp } & 0.002 & 0.002 & 0.08 & 158 & \text { n.s. } \\ & \text { Ramp-away } & 0.002 & 0.003 & 0.06 & 124 & \text { n.s. } \\ & \text { Ramp-back } & 0.005 & 0.003 & 0.29 & 43 & \text { n.s. } \\ \text { Step contralateral to striate lesion } & & & & & \\ \text { Monkey M23 } & \text { No ramp } & -0.003 & 0.004 & -0.03 & 176 & \text { n.s. } \\ & \text { Ramp-away } & 0.005 & 0.008 & 0.06 & 101 & \text { n.s. } \\ & \text { Ramp-back } & -0.006 & 0.008 & -0.08 & 87 & \text { n.s. }\end{array}$

Regression, adjusted saccadic amplitude versus latency

Step ipsilateral to striate lesion

$\begin{array}{lrrrrrr}\text { Monkey M23 } & \text { Ramp-away } & 22.9 & 4.51 & 0.42 & 123 & p<0.001 \\ & \text { Ramp-back } & -11.0 & 3.98 & -0.40 & 43 & p<0.01 \\ \text { Step contralateral to striate lesion } & & & & & \\ \text { Monkey 23 } & \text { Ramp-away } & 20.1 & 7.29 & 0.27 & 101 & p<0.01 \\ & \text { Ramp-back } & -41.2 & 8.17 & -0.48 & 87 & p<0.001\end{array}$

Whereas the correlations between saccadic error and latency were not significant, those between adjusted saccadic amplitude and latency were significant. SES, standard error of slope in $\mathrm{deg} / \mathrm{sec} ; r=$ correlation coefficient; $n=$ number of trials. Slope units are $\mathrm{deg} / \mathrm{sec}$. Monkey M23.

Smooth pursuit induced by a quasistabilized stimulus. In the monkeys fitted with the magnetic search coil, eye-position measurcment was so accurate that the mirror-controlled target could be used as a quasistabilized image. This could then be used to assess the effectiveness of stimulus-position error in inducing or maintaining smooth pursuit in the absence of significant retinal stimulus velocity. We used 2 different methods to assess the response of the smooth pursuit system to a parafoveally quasistabilized image. The first was to use this stimulus to maintain an established smooth pursuit movement. Figure 14 shows examples of smooth pursuit directed to both the left and right for monkey M23. In each experiment illustrated in Figure 14, $A-C$, the trial began with the monkey performing smooth pursuit. The stimulus was then jumped in the direction of the pursuit, and quasistabilized thereafter. The monkey accurately maintained smooth pursuit when the stimulus was quasistabilized in the field ipsilateral to the lesion (Fig. 14A), but not when

Table 4. Mean postsaccadic pursuit gains (eye velocity/target velocity) for horizontal and vertical smooth pursuit

\begin{tabular}{|c|c|c|c|c|c|}
\hline & Direction & Gain & SD & $n$ & $\begin{array}{l}\text { Signifi- } \\
\text { cance }\end{array}$ \\
\hline \multicolumn{6}{|c|}{ Step contralateral to striate lesion } \\
\hline \multirow[t]{2}{*}{ Monkey M19 } & Vertical & 0.04 & 0.09 & 69 & \\
\hline & Horizontal & 0.10 & 0.22 & 188 & \\
\hline \multirow[t]{2}{*}{ Monkey M23 } & Vertical & 0.05 & 0.37 & 56 & \\
\hline & Horizontal & 0.07 & 0.12 & 94 & \\
\hline \multicolumn{6}{|c|}{ Step ipsilateral to striate lesion } \\
\hline \multirow[t]{2}{*}{ Monkey M19 } & Vertical & 0.34 & 0.14 & 72 & $p<0.0001$ \\
\hline & Horizontal & 0.48 & 0.12 & 53 & $p<0.0001$ \\
\hline \multirow[t]{2}{*}{ Monkey M23 } & Vertical & 0.67 & 0.29 & 42 & $p<0.0001$ \\
\hline & Horizontal & 0.80 & 0.15 & 94 & $p<0.0001$ \\
\hline
\end{tabular}

Same data as plotted in Figure 7. Significance levels are for differences between mean pursuit gains in fields ipsilateral and contralateral to the striate lesion. the stimulus was quasistabilized in the field contralateral to the lesion (Fig. 14B). The decrement of eye velocity when the stimulus was quasistabilized in the affected ficld rescmbled the decrement of velocity when the target light disappeared entirely

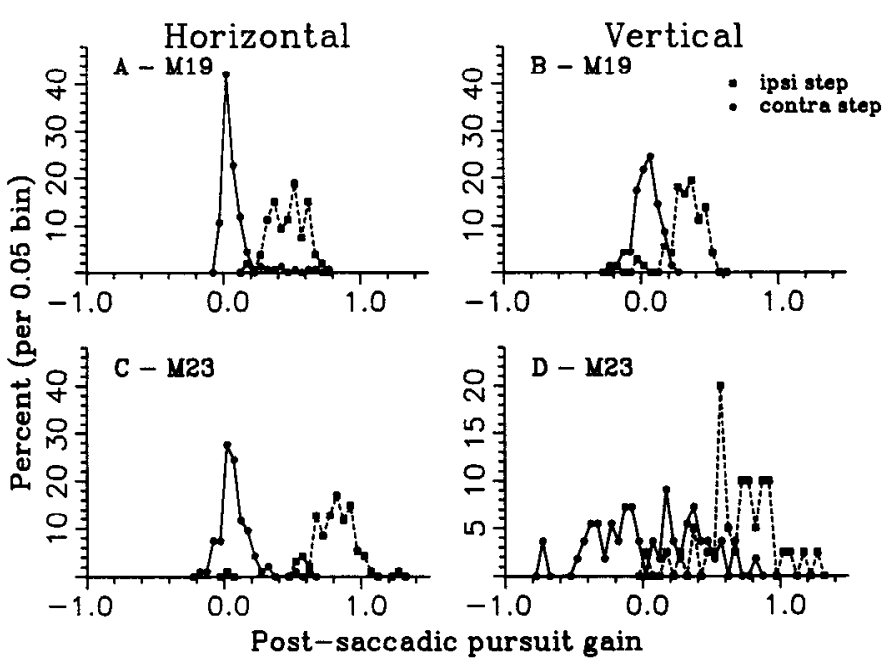

Figure 12. Distribution of postsaccadic pursuit gains (eye velocity/ target velocity) for horizontal and vertical smooth pursuit. Each graph shows the percentage of individual trials, in 0.05 wide bins, plotted against gain. Circles represent gains for steps into the field contralateral to the lesion, and squares represent gains for steps into the field ipsilateral to the lesion. $A, C$, Gain of horizontal pursuit movements after horizontal stimulus steps. For monkey $\mathrm{M} 19(A)$ there were 53 ipsilateral and 188 contralateral trials, and for monkey M23 $(C)$ there were 94 ipsilateral and 94 contralateral trials. $B, D$, Gain of vertical pursuit movements after oblique stimulus steps. For monkey M19 $(B)$ there were 72 ipsilateral and 69 contralateral trials, and for monkey M23 (D) there were 42 ipsilateral and 56 contralateral trials. For $A-D$, the mean gains for trials with steps into the field ipsilateral to the lesion were significantly different from the mean gains for trials with steps into the field contralateral to the lesion $(p<0.0001)$. Note than when the stimulus was moving in the affected field, the pursuit gains clustered near zero, reflecting postsaccadic pursuit velocities near zero. 


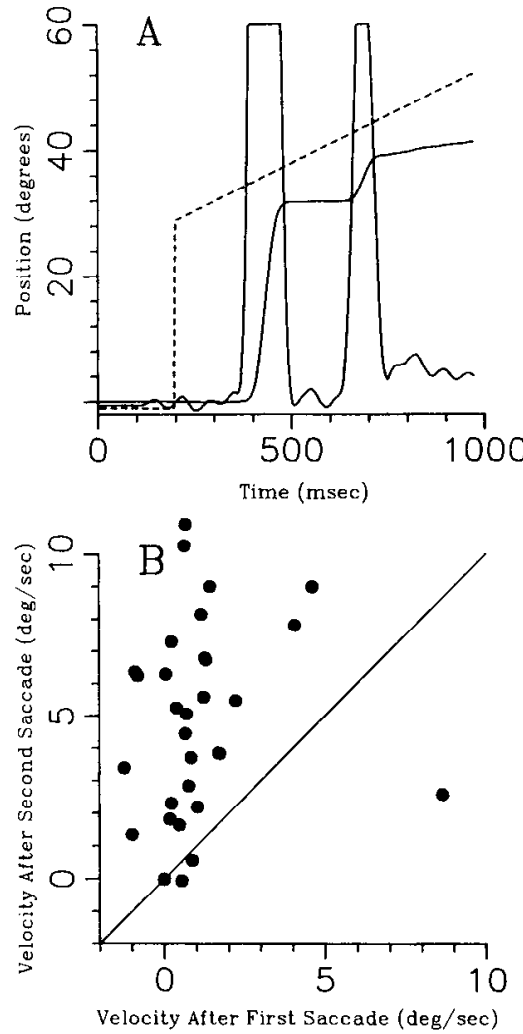

Figure 13. Eye velocity after the second saccade to step-ramp largets presented in the field contralateral to the lesion (M23). A, Horizontal components of eye position (smooth solid line), eye velocity (wavy solid line), and stimulus position (dashed line) for a stimulus stepped into the field contralateral to the striate lesion and then ramped away from the center of gaze. Note that there were 2 saccades. The second saccade was followed by an appreciable velocity even though the stimulus never appeared in the intact field. The velocity calibration is identical in deg/ sec to the position calibration. Sample rate, $250 \mathrm{~Hz}$. B, Scatter diagram of velocity immediately after second saccade, plotted against velocity immediately after first saccade. Data include all trials in the distribution shown in Figure $6 B$, for which there were 2 saccades, both limited to the field contralateral to the lesion. Trials with equal velocities after first and second saccades would plot on diagonal line, drawn for comparison to actual data.

(Fig. 14C). A simple explanation of the similarity between the results in Figure 14, $B$ and $C$, would, of course, be that the monkey could not see the quasistabilized image at all in the field contralateral to the lesion. However, the monkey did make an accurate saccade to the same stimulus presented without stabilization (Fig. 14D), and also made saccades to targets stabilized in the impaired field, as discussed below.

Figure 15 shows the distribution of times for eye velocity to reach zero in the pursuit maintenance task for all trials on 2 successive days for monkey M23. The mean time for pursuit maintenance (time to zero velocity) of an image stabilized $3^{\circ}$ into the field ipsilateral to the lesion was $995 \mathrm{msec}$, and this was an underestimate of the capacity of the system because the trials were usually only $1000 \mathrm{msec}$ long. The mean for pursuit maintenance of an image stabilized $3^{\circ}$ into the field contralateral to the lesion was $400 \mathrm{msec}$. The mean time to zero velocity for trials in which the light went out during pursuit was $290 \mathrm{msec}$. The difference between the latter 2 results was significant $(p<$ 0.0001 ). Thus, the image held open-loop in the field contralateral to the lesion must have had some effect on the maintenance

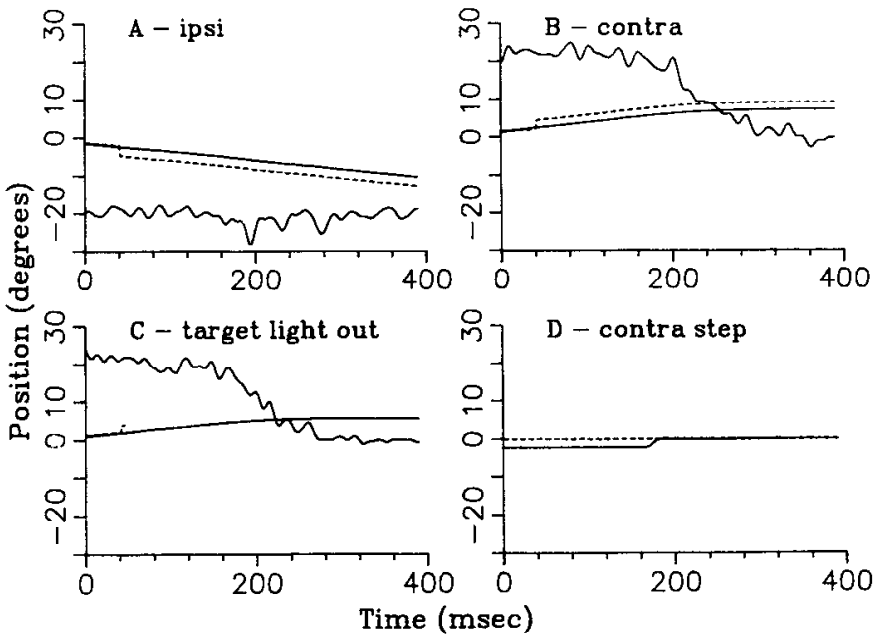

Figure 14. Use of a quasistabilized image to maintain smooth pursuit movements (M23). In each diagram, horizontal stimulus position (dashed line), eye position (smooth solid line), and eye velocity (wavy solid line) are superimposed. The velocity calibration is identical in $\mathrm{deg} / \mathrm{sec}$ to the position calibration. $A$, A pursuit velocity of $20 \% \mathrm{sec}$ was maintained throughout the interval illustrated, when the stimulus was quasistabilized $3^{\circ}$ into the field ipsilateral to the lesion. $B$, Decrement of an initial $20^{\circ} / \mathrm{sec}$ eye velocity when the stimulus was quasistabilized in the field contralateral to the lesion. Note the dramatic decrement of eye velocity beginning about $160 \mathrm{msec}$ after quasistabilization. $C$, Effect of turning the target light off upon pursuit velocity. $D$, Demonstration of the monkey's ability to make an accurate saccade to a stimulus stepped $3^{\circ}$ into the field contralateral to the lesion. Sample rate, $1 \mathrm{kHz}$.

of pursuit. For monkey M19, the difference in time to zero velocity between light out and stabilization in the field contralateral to the lesion, although not significant, was in the appropriate direction. However, the numbers of trials were few with this monkey. Table 5 lists mean times to zero velocity for both monkeys.

Because the quasistabilization technique was associated with some minimal retinal slip, it is possible that this was the only stimulus that was driving smooth pursuit, and that the quasistabilization technique merely served to keep the slip stimulus in the impaired field. To examine this possibility, we used the same open-loop method to combine a small $\left(1^{\circ}-3^{\circ}\right)$ step in the established pursuit direction with a small $\left(1^{\circ}-2^{\circ} / \mathrm{sec}\right)$ slip in the opposite direction. If slip direction were the only important stimulus for pursuit, then, in such a conflict situation, the pursuit should follow the slip and not the step. The 2 normal monkeys tested for this both maintained pursuit in the direction of the step, even though the retinal slip was in the opposite direction. It may be concluded from this that position error itself was the significant stimulus for pursuit, and that position errors maintained in the impaired field were nearly incapable of sustaining pursuit.

The second method for assessing the effectiveness of a position error as a stimulus for smooth pursuit was to use the parafoveally quasistabilized image to initiate, rather than simply to maintain, pursuit. One of the monkeys (M19) routinely initiated pursuit when its fixation point was stepped into the intact field and then quasistabilized there. Figure $16 \mathrm{~A}$ shows the result when the monkey attempted to fixate an image quasistabilized at $3^{\circ}$ in the field ipsilateral to the lesion. Note that although the monkey made a number of saccades, the eye velocity between saccades gradually increased, indicating that the monkey also generated 


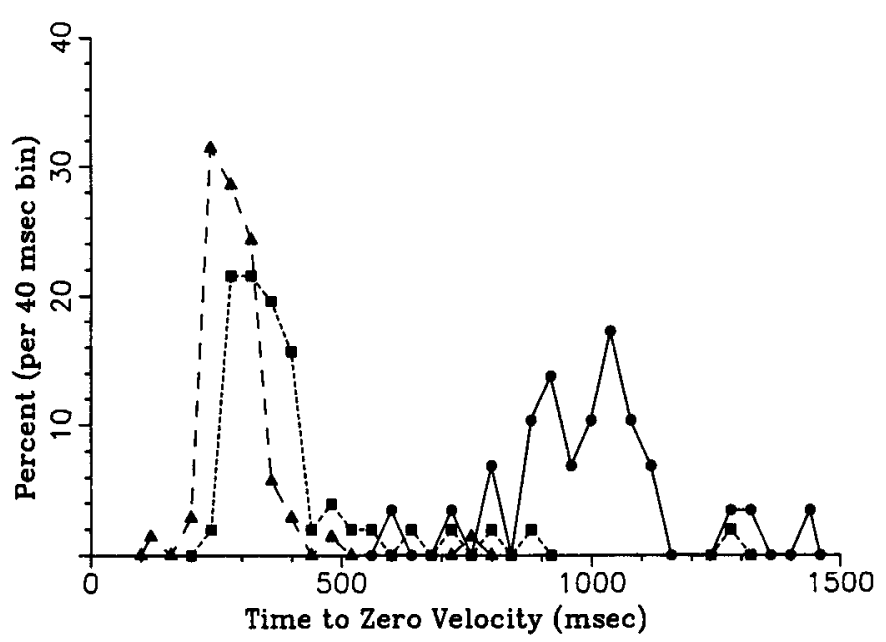

Figure 15. Distributions of the durations of pursuit of quasistabilized images (M23). The percentage of individual trials per 40-msec-wide bin is plotted against the corresponding time for smooth pursuit velocity to reach zero (time from image quasistabilization to zero velocity). Circles, times to zero velocity for steps into the field ipsilateral to the lesion (mean, $995 \mathrm{msec} ; n=29$ ); squares, times to zero velocity for steps into the field contralateral to the lesion (mean, $400 \mathrm{msec}, n=51$ ); and triangles, times to zero velocity for trials in which the light was extinguished during ramp pursuit towards the field contralateral to the lesion (mean, $290 \mathrm{msec} ; n=70$ ). The mean for trials when the image was quasistabilized in the field contralateral to the lesion was statistically different from the mean for trials with image quasistabilized in the field ipsilateral to the lesion and from the mean for trials during which the light was extinguished.

smooth pursuit movements. When the gaze angle reached an eccentricity of about $30^{\circ}$, pursuit velocity fell off as the eye approached the end of its range of movement. When the monkey attempted to fixate a stimulus stepped into the field contralateral to the lesion (Fig. 16B), it did not generate any similar pursuit velocity between saccades. After several quasistabilized trials, the monkeys frequently attempted to capture the target by making hypermetric saccades (Fig. 16B). Calibration checks of the mirrors at the times of these trials failed to reveal any problem. Instead, the monkeys appeared to have developed an adaptive strategy in an attempt to deal with the task (FitzGibbon et al., 1986).

Stimulus-velocity and stimulus-position effects could be revealed simultaneously by having the monkey look at a stimulus permitted to move in the vertical dimension while quasistabilized in the horizontal dimension. Figure 17 shows such an experiment; the stimulus was quasistabilized in the horizontal dimension, $3^{\circ}$ away from the fovea, and moved in the vertical dimension with sinusoidally varied velocity. When this was done in the field ipsilateral to the lesion (monkey M19), the monkey generated a combination of horizontal smooth pursuit movements and saccades (Fig. 17A) and simultaneously pursued the vertical sinusoidal motion of the target with reasonable accuracy (Fig. 17B). With the image quasistabilized in the field contralateral to the lesion, however, not only did the monkey fail to generate smooth pursuit movements horizontally-although it did make saccades to the target (Fig. 17C)-it also failed to generate sinusoidal vertical pursuit, following the target instead with saccades (Fig. 17D). This failure to generate pursuit of a moving stimulus continued for several seconds, extending the result of the step-ramp experiments in which the moving

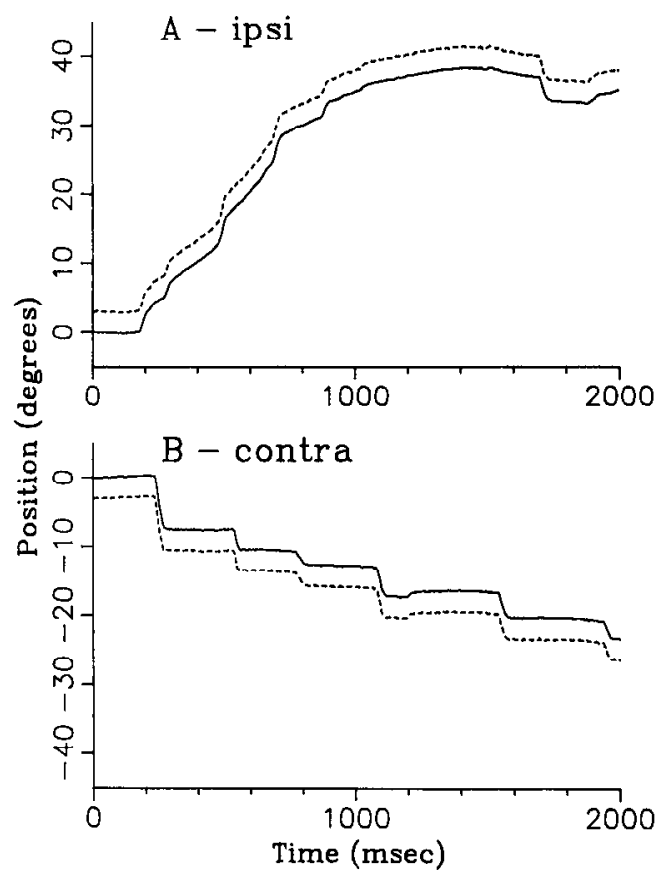

Figure 16. Efforts to fixate a parafoveally quasistabilized image (M19). At the beginning of each trial, the stimulus (dashed line) was stepped horizontally $3^{\circ}$ from the fovea. For the remainder of the trial, the eyeposition signal (solid line) was added to target position, thereby keeping image position stationary. Target position was updated at $1 \mathrm{msec}$ intervals. $A$, Image quasistabilized in the field ipsilateral to the lesion. The monkey made a series of saccades, each of which was followed by epochs of smooth pursuit. $B$, Image quasistabilized in the field contralateral to the lesion. The monkey made a series of saccades but there was no intersaccadic smooth pursuit. Samplc ratc, $250 \mathrm{~Hz}$.

stimulus was confined to the impaired field for a few hundred milliseconds at most.

Permanence of deficits. The deficits described above seemed to be permanent. The monkeys were studied for up to 27 months after surgery without showing improvement in either the accuracy of saccades to moving targets or in the development of pursuit to targets limited to one hemifield. More than 1 year after the data illustrated in Table 1 were recorded, monkey M19 was undershooting stimuli moving away from the center of gaze at $15 \% \mathrm{sec}$ in the field contralateral to the lesion with a mean

\section{Table 5. Mean times to zero velocity}

\begin{tabular}{|c|c|c|c|c|}
\hline & Time & SD & $n$ & Significance \\
\hline \multicolumn{5}{|c|}{ Quasistabilized ipsilateral to striate lesion } \\
\hline M19 & 924 & 145 & 18 & $p<0.0001$ \\
\hline M23 & 995 & 174 & 29 & $p<0.0001$ \\
\hline \multicolumn{5}{|c|}{ Quasistabilized contralateral to striate lesion } \\
\hline M19 & 389 & 181 & 27 & \\
\hline M23 & 400 & 180 & 51 & \\
\hline \multicolumn{5}{|c|}{ Light turned off during pursuit } \\
\hline M19 & 364 & 42 & 13 & $p=0.31$ \\
\hline M23 & 290 & 78 & 70 & $p<0.0001$ \\
\hline
\end{tabular}

Same data as plotted in Figure 15 for M23. Significance levels are for differences between mean times to 0 velocity for image quasistabilized in fields ipsilatera and contralateral to striate lesion, and for target light turned off during pursuit and image quasistabilized in the field contralateral to the lesion. 


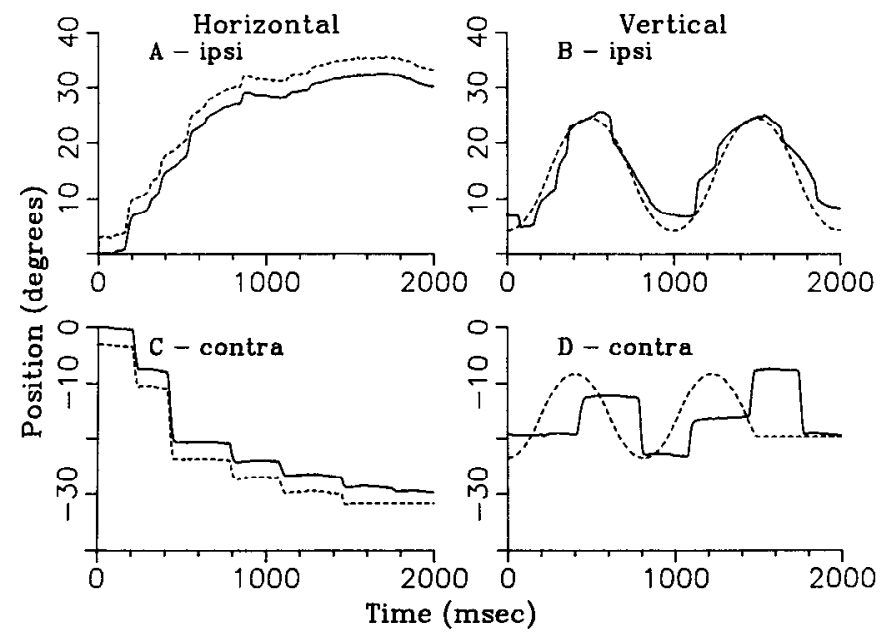

Figure 17. Pursuit of image quasistabilized in the horizontal dimension and moving with sinusoidally varied velocity in the vertical dimension (M19). $A$, Horizontal component, and $B$, vertical component of stimulus position (dashed line) and eye position (solid line) when the stimulus was stepped into the field ipsilateral to the lesion. Note that there was reasonably accurate smooth pursuit in the vertical dimension, and pursuit interspersed with saccades in the horizontal dimension. $C$, Horizontal component, and $D$, vertical component of stimulus pesition and eye position when the stimulus was stepped into the field contralateral to the lesion. Note that both the vertical and horizontal components of eye position contain saccades to the target but not smooth pursuit movements. Sample rate, $250 \mathrm{~Hz}$.

error of $-2.2^{\circ}$ (compared with $-2.81^{\circ}$ initially), and overshooting stimuli moving towards the center of gaze with a mean error of $2.58^{\circ}$ (compared with $3.59^{\circ}$ initially). The decrease in these errors is probably due to the decreased velocity of the target $(30 \% \mathrm{sec}$ initially versus $15 \%$ sec later), rather than to any recovery.

\section{Discussion}

Thesc experiments have shown that the oculomotor system of a monkey with a unilateral striate lesion is virtually blind to the velocity of moving targets in the affected hemifield. As a consequence, the monkey with a unilateral striate lesion cannot adjust the amplitude of a saccade for the ongoing velocity of its target, nor does the monkey modify saccadic latency according to the direction of movement of the target. The smooth pursuit system of a monkey with a unilateral striate lesion cannot generate accurate smooth pursuit eye movements to stimuli moving in the contralateral hemifield, nor can it generate eye velocity from the position of a target quasistabilized in the contralateral field. The same monkey has no problem with the motor performance of eye movements into either hemifield. Thus, in our monkeys, foveal pursuit appeared normal in both directions and saccades to stationary targets were, on the whole, accurate. Instead, the deficits in the monkeys' behavior seemed almost entirely due to their inability to estimate the velocity of the stimuli located in the field contralateral to the lesion, or to use the position of a stimulus quasistabilized in the impaired field to calculate required eye velocity. Since we performed the experiments at only one target intensity, well into the photopic range, and at one contrast, it is possible that our monkeys did not have an absolute deficit, but a threshold one, and that the deficit may have diminished with higher contrasts or intensities. Nonetheless, the striking difference between the monkey's performance in finding the position of a target and in processing its velocity or calculating eye velocity from its position suggests that striate cortex is usually critical for these functions.

\section{Effect of striate lesions on saccadic eye movements}

Mohler and Wurk (1977) showed that monkeys with partial striate lesions in one hemisphere lose the ability to make saccades into the affected field for about 3 weeks, but that this ability is recovered simultaneously with the ability to detect stimuli flashed in this field. When tested some months after the surgery, our monkeys also made accurate saccades to stationary targets in the field contralateral to the striate lesion. They had a slight tendency to overshoot targets in the field contralateral to the lesion, but this may have been a deliberate attempt to place the target in the intact field rather than a problem with target localization. The only evidence of difficulty in guiding saccades to stationary targets was that there was a slightly higher standard deviation of saccadic error when the stimulus stepped into the impaired field than when it stepped into the intact field (roughly 1.5 compared to 0.6 ).

The monkeys could also locate moving targets, even though they made inaccurate saccades to them. The amplitude of saccades to the moving target consisted of the target step size plus an amount proportional but not equal to the change in target position during the saccadic latency period. This is what one would expect if the monkey had measured the static position of the moving target at some time after the target began to move, and then used this static measure to generate a saccade. However, this strategy ignores subsequent target movement. The deficit was not in finding the target, but in predicting where it would be. Heywood and Churcher (1981) have suggested that humans do not necessarily use a velocity-predictive strategy in making saccades to moving targets. The present experiments argue that monkeys normally do.

A simple possible alternative to the predictive strategy would be that the monkey simply adds a smooth pursuit movement to the saccade to come up with the accurate saccadic amplitude. This is unlikely, however, bccause an accurate movement would require pre- as well as postsaccadic smooth pursuit velocity to be equal to the velocity of the target. Such high-gain presaccadic smooth pursuit was never seen.

In these experiments, the portion of saccadic amplitude due to the ramp movement changed in proportion to saccadic latency, but the error did not, suggesting that the monkey could use the position of the moving target rather than only the initial target step to generate a saccade. These results support the hypothesis that the saccadic reaction period can be divided into separate processes (Becker and Jürgens, 1979; Fischer and Boch, 1983): (1) the decision to break fixation and make a saccade to a new target; (2) the localization of the target in space; and (3) the specification of the desired coordinates of the saccade and the use of these coordinates by the brain stem oculomotor region to generate the eye movement. Because of the regular relationship between saccadic latency and saccadic amplitude, the variability in saccadic latency must arise during the time period before the specification and generation process begins. Fischer and Boch (1983) have described express saccades in the monkey in a paradigm in which the fixation point disappears several hundred milliseconds before the stimulus appears. Under these circumstances, monkeys make short-latency (70-80 msec) saccades with surprisingly little variance in reaction time. The time used for this short-latency saccade involves localizing the target 
as well as programming the motor aspects of the saccade, but the decision to break fixation and make a saccade is taken when the fixation point disappears several hundred milliseconds before the target appears. Thus, the variability in saccadic latency seems to arise predominantly during the initial decision process.

One of the factors affecting the saccadic reaction time is the direction of target motion. Monkeys seem to obey a law of "minimization of saccadic effort." If the target is moving away from the center of gaze, they make rapid saccades, as if to minimize the amplitude of the saccade needed to acquire the target. If the target is moving towards the center of gaze, the monkeys wait, since the necessary saccades grow shorter as fixation time increases. Monkeys with striate lesions do not make this distinction; instead, their reaction time is unaffected by the direction of stimulus motion. Thus, the striate cortex is part of the cortical pathway necessary in order to give the saccadic system not only the target's speed, but also its direction of motion. Because of this, the deficit is best described as an impairment in processing target velocity rather than merely one of target speed.

\section{Effect of striate cortical lesions on smooth pursuit}

We have shown that monkeys with unilateral striate lesions cannot make smooth pursuit eye movements in response to stimuli moving in the hemifield contralateral to the lesion. This deficit resembles that seen in the saccadic system: the oculomotor system is blind to the retinal velocity of targets in the field contralateral to a unilateral striate lesion. However, this inability to appreciate retinal slip velocity is not the only deficit caused by a unilateral striate lesion. The monkeys cannot generate eye velocity from stimulus-position error alone, since they can neither initiate nor maintain smooth pursuit of stimuli quasistabilized in the contralateral hemifield. Thus the deficit must involve more than an inability to appreciate retinal stimulus velocity.

Kommerell and Täumer (1972) showed that humans can generate smooth pursuit to foveal or extrafoveal afterimages, and that the quality of the movement depends on the subject's attention. We used an open-loop technique to approximate a stabilized afterimage by feeding back the monkey's eye position to the mirror position. This method must have caused some retinal slip, because the eye coil was calibrated to $15^{\prime}$ of arc, as was the mirror, and the minimum increment of mirror movement was $5^{\prime}$ of arc. In addition, during saccades, mechanical characteristics caused the mirror to lag the eye, although we partially compensated for this by adding a velocity term to increase the mirror drive for high velocities. One interpretation of our results is that the minimal retinal slip in the quasistabilized paradigm is the only stimulus parameter maintaining smooth pursuit, and since we have already established that the monkeys with unilateral striate lesions cannot respond to stimulus velocity in their impaired field, it is not surprising that they do not maintain or initiate pursuit of a target quasistabilized in this field. This explanation is unlikely, however, for several reasons. First, in recording from velocity-sensitive neurons in the area MI during pursuit of an image stabilized by techniques similar to ours, Wurtz and Newsome (1985) showed that the ncurons did not discharge under these circumstances, implying that retinal slip was minimal. Second, according to most models of the smooth pursuit system, stimulus velocity and stimulus position affect eye acceleration, not eye velocity (Lisberger et al., 1981). This makes intuitive sense because, as eye velocity increases during smooth pursuit, retinal slip velocity decreases. If slip velocity only affected eye velocity, it would be impossible to maintain smooth pursuit. However, if retinal slip velocity affected eye acceleration directly, zero retinal slip velocity would result in zero eye acceleration, and pursuit would be maintained. Thus, if the only deficit in the impaired field were an inability to detect retinal slip, resulting in a slip signal of zero, pursuit maintenance should not have been affected. However, in our experiments, pursuit was not maintained by a stimulus stepped and then quasistabilized in the field contralateral to the lesion, implying that the striate cortex must provide some factor in addition to retinal slip velocity.

There are 3 possibilities for this other factor. The first is that the striate cortex sends a quantitative signal related to the position error. This signal could drive eye acceleration directly, or it could be interpreted as stimulus motion (Carl and Gellman, 1985), which would then drive eye acceleration. This must be the case in the pursuit initiation paradigm in which the position step is the only signal driving pursuit. The second is that the striate cortex is necessary to identify a stimulus for smooth pursuit, presumably enabling the attentional function identified by Kommerell and Täumer (1972). In this case the quasistabilized image might still maintain pursuit while yielding a zero acceleration signal. A third, more general possibility, is that the smooth pursuit system ultimately requires an estimate of target velocity in spacc to drive eye velocity. The system may use some combination of target-position error, retinal slip velocity, and an efference copy of eye velocity to make this estimation, and the visual input for these calculations must traverse striate cortex. Our data do not allow us to distinguish among these hypotheses.

That only one of our monkeys would initiate pursuit to establish images was not unexpected. Even though a position error can provide an eye-acceleration signal for pursuit maintenance (Lisberger and Westbrook, 1985), not all monkeys readily initiate pursuit to a stabilized position error (Dürsteler et al., 1987). Furthermore, in our pursuit maintenance paradigm we never saw eye acceleration, but at best saw little or no eye deceleration. It is therefore possible that our monkeys were not sufficiently motivated to accelerate in response to most position errors, and that the position error usually served only to select the target as a stimulus for the pursuit system. Nonetheless, it is striking that some aspect of the quasistabilized target other than its retinal slip velocity is rendered inaccessible to the smooth pursuit system by a striate lesion.

The first to observe that striate cortex was necessary for smooth pursuit were Zee and colleagues (1982), who showed that monkeys with bilateral occipital lobectomies were incapable of smooth pursuit movements 4 weeks after surgery. Howcver, smooth pursuit performance recovered to normal levels 8 weeks after the bilateral occipital ablations in those monkeys. More recently, Tusa and colleagues (1986) showed that monkeys with hemispherectomies have both bidirectional velocity deficits and unidirectional foveal pursuit deficits. Striate cortex projects directly to area MT in the superior temporal sulcus, which has been shown to be specifically involved in the processing of stimulus motion (Maunsell and Van Essen, 1983; Van Essen and Maunsell, 1983). Furthermore, Newsome et al. (1985) showed that focal lesions of area MT induced by injections of ibotenic acid resulted in smooth pursuit and saccadic deficits similar to those described in this report. The monkeys with MT lesions were able to make smooth pursuit movements in all directions, 
but were unable to derive velocity information, regardless of movement direction, from the specific portion of the visual field represented by the damaged portion of area MT. Unlike monkeys with striate lesions, however, monkeys with foveal MT lesions had intact pursuit eye movements to stabilized images (Dursteler et al., 1987). This difference between monkeys with striate lesions and those with MT lesions implies that the pathway by which stimulus position is translated to eye velocity includes striate cortex, but diverges from the stimulus-velocity pathway before area MT.

The deficit after unilateral striate lesions seems to be permanent. One of the monkeys with an implanted eye coil (M19) was studied for 27 months after surgery, without recovery. This result contrasts with those of both chemical lesions of MT, where the deficits last only for 1 week (Newsome et al., 1985; Dürsteler et al., 1987), and bilateral occipital ablations, where the deficits are also much shorter-lived (Zee et al., 1982). Ablation of MT leaves the velocity-tuned system within V1 intact, so it is less surprising that the monkey should recover quickly. The recovery described by Zee et al. (1982) is not so easily explained. If striate cortex were the sole source of velocity information to the pursuit system, then monkeys with bilateral lesion of this tissue should be unable to perform foveal smooth pursuit. Yet, Zee et al. (1982) reported that bilateral occipital lobectomy resulted in only a transient inability of rhesus monkeys to pursue a spot of light. The deficit was total 4 weeks after surgery, but the monkeys' sinusoidal pursuit had returned to normal 8 weeks after surgery, although the monkeys were still unable to develop optokinetic responses to rapidly moving stimuli.

There are several possible explanations for this difference in the recovery of pursuit between monkeys with unilateral and bilateral striate lesions. First, the monkey with a unilateral striate lesion presumably relies upon the intact striate cortex for input to the smooth pursuit system. However, a monkey with a bilateral striate lesion is left with only subcortical and residual extrastriate visual mechanisms, and so may use them more fully. The effect could be analogous to the tendency of monkeys with unilateral dorsal rhizotomies to avoid use of the deafferented limb until the intact one is mechanically restrained (Knapp et al., 1963). That some velocity processing does remain in the absence of striate cortex has been shown by Rodman et al. (1985), who have recently demonstrated some residual directionally selective activity in neurons in monkey MT following lesions of striate cortex. A second possibility is that there is a motor adaptation in response to this diminished sensory input. In the monkey with bilateral lesions, the reduction in afferent input is uniform throughout the visual field, and it is possible that the oculomotor system increases the smooth pursuit gain to compensate for this reduction. Such an adaptation has been described for humans with weakness of the extraocular muscles (Optican et al., 1985). However, in the monkey with a unilateral lesion, a discrepancy exists between an appropriate velocity signal from the intact visual hemifield and a reduced signal from the affected field. Assuming that changes in smooth pursuit gain are not field-specific, it would be maladaptive in this case to increase the gain of the efferent signal, since the pursuit of targets in the affected field would improve at the expense of smooth pursuit movements to targets in the intact field. Still another possibility is that the remaining striate cortex may exercise a cross-suppressive influence over remaining visual structures in the damaged hemisphere, including the superior colliculus and the pretectum, which still receive direct retinal projections. The superior colliculus in the monkey has predominantly pandirectional visual activity (Goldberg and Wurtz, 1972), and although a few directionally selective cells have been described (Schiller and Koerner, 1971; Goldberg and Wurtz, 1972), motion-selective activity in the superior colliculus of the monkey is far less common than in the cat (Sterling and Wickelgren, 1969). The monkey's pretectum, particularly the nucleus of the optic tract, contains neurons that are sensitive to stimuli with a wide range of velocities (Hoffmann, 1985; Mustari et al., 1985). However, the velocity sensitivity of these neurons is derived from both retinal and cortical inputs. Monkeys with bilateral occipital ablations have optokinetic nystagmus that is driven by low retinal slip velocities and has a temporal-nasal preponderance (Zee et al., 1986). Thus, in the absence of occipital cortex, monkeys behave as if their optokinetic system were driven by pretectal neurons similar to those found in the cat and rabbit, whose cells are tuned to large-field motion at low speeds and are predominantly selective for temporal-nasal motion (Collewijn, 1975; Hoffmann, 1981). If the mechanism for smooth pursuit movements in the cases with bilateral occipital lobectomy has its sensory source in these subcortical regions, it is possible that an intact hemisphere can suppress the contralateral subcortical regions, as Sprague (1966) has demonstrated in the cat. If so, then the removal of the remaining striate cortex in a monkey with a unilateral striate ablation would restore to the smooth pursuit and saccadic systems more efficient access to those subcortical velocity-analysis systems, which perform only at low gain and long latency in the monkey with a unilateral lesion.

\section{On seeing moving objects and remaining blind to their velocity}

The major result of these experiments is the striking finding that the oculomotor system of a monkey with a unilateral striate lesion sees the target's position but not its velocity. The appreciation of velocity requires that target position be sampled over time. From the work of Barlow and Levick (1965) in the rabbit retina to very recent findings by Mikami et al. (1986a, b; Newsome et al., 1986) in monkey striate cortex and area MT, many studies have shown that neural systems sample discrete position changes to derive velocity. These studies have demonstrated that neurons tuned for velocity have complicated anisotropic inhibitory structures in their receptive fields, causing them to discharge in response to a series of stationary stimuli displaced in one, but not in the opposite, direction. Although the present studies have been concerned with striate cortex itself, the major input to area MT is derived from striatc cortex both directly and indirectly via area V2 (Zeki, 1976; Ungerleider and Mishkin, 1979; Maunsell and Van Essen, 1983; Ungerleider and Desimone, 1986).

The existence of velocity-tuned neurons provides the rest of the nervous system with a very short-term measure of velocity. Since striate cortex and area MT have already performed a 2-point comparison, the remainder of the nervous system need only sample these neurons once to appreciate the velocity of a stimulus, much as the driver of a car need only glance at the speedometer to know the car's speed, rather than having to sample the scenery twice and make a calculation. For some aspects of velocity discrimination - for example, to answer the question, "Did the stimulus move?"- the latter method is satisfactory. We would postulate that the monkey could use such a multiple-sampling strategy to discriminate between moving and stationary objects, and even to infer the direction of motion, but not quickly enough to inform the saccadic system. Adjusting 
saccadic amplitude and latency requires knowledge of the instantaneous velocity of the target. Since the monkey with a lesion of striate cortex is devoid of a velocity signal from the visual field contralateral to the lesion, it treats all stimuli within that field as having zero instantaneous velocity. When this is the case, the oculomotor system must process a moving stimulus as a series of snapshots of a target: although the target moves between snapshots, at any given time the static position signal is fairly accurate. However, judgments cannot be made about the motion of the target from the position signal alone. This dissociation between stimulus velocity and changing stimulus position has been reported by a patient, described as having bilateral temporal-occipital lesions, who had full visual fields but no sensation of visual motion: "People were suddenly here or there but I have not seen them moving" (Zihl et al., 1983).

Our data demonstrate that the oculomotor system of a monkey with a unilateral striate lesion is blind to the velocity of a target whose position it can still perceive. This deficit affects not only the metrics of saccadic and smooth pursuit eye movements, but also the reaction times for saccades, which normally vary as a function of the direction of movement of the stimulus. The deficit for the smooth pursuit system includes both an inability to analyze retinal slip accurately and an inability to use stabilized images to calculate eye velocity. Since the monkey is capable of the appropriate smooth pursuit and saccadic eye movements under other circumstances, it is reasonable to assume that the deficit is not in motor performance per se, but in the analysis of stimulus velocity from retinal slip and position error, and in the appreciation of the instantaneous aspects of target motion.

\section{References}

Barlow, H. B., and W. R. Levick (1965) The mechanism of directionally selective units in rabbit's retina. J. Physiol. (Lond.) 178:477504.

Barmack, N. H. (1970) Modification of eye movements by instantaneous changes in the velocity of visual targets. Vision Res. 10:14311441.

Becker, W., and R. Jürgens (1979) An analysis of the saccadic system by means of double step stimuli. Vision Res. 19: 967-983.

Benevento, L. A., and K. Yoshida (1981) The afferent and efferent organization of the lateral geniculo-prestriate pathways in the macaque monkey. J. Comp. Neurol. 203: 455-474.

Bond, H. W., and P. Ho (1970) Solid miniature silver-silver chloride electrodes for chronic implantation. Electroencephalogr. Clin. Neurophysiol. 28: 206-208.

Carl, J. R., and R. S. Gellman (1985) Human smooth pursuit: The responses to conflicting velocity and position stimuli. Soc. Neurosci. Abstr. 11: 78 .

Collewijn, H. (1975) Direction-selective units in the rabbit's nucleus of the optic tract. Brain Res. 100: 489-508.

Dürsteler, M. R., R. H. Wurtz, and W. T. Newsome (1987) Directional pursuit deficits following lesions of the foveal representation within the superior temporal sulcus of the macaque monkey. J. Neurophysiol. 57: 1262-1287.

Fischer, B., and R. Boch (1983) Saccadic eye movements after extremely short reaction times in the monkey. Brain Res. 260: 21-26.

FitzGibbon, E. J., M. E. Goldberg, and M. A. Segraves (1986) Short term saccadic adaptation in the monkey. In Adaptive Process in the Visual and Oculomotor Systems, E. Keller and D. Zee, eds., pp. 329333, Pergamon, New York.

Fuchs, A. F. (1967) Saccadic and smooth pursuit eyc movements in the monkey. J. Physiol. (Lond.) 191: 609-631.

Gattass, R., C. G. Gross, and J. H. Sandell (1981) Visual topography in V2 in the macaque. J. Comp. Neurol. 201: 519-539.

Goldberg, M. E. (1983) Studying the neurophysiology of behavior: Methods for recording single neurons in awake behaving monkeys.
In Methods in Cellular Neurobiology, Vol 3, chapt. 8, J. L. Barker and J. F. McKelvy, eds., pp. 225-248, Wiley, New York.

Goldberg, M. E., and R. H. Wurtz (1972) Activity of superior colliculus in behaving monkey: I. Visual receptive fields of single neurons. J. Neurophysiol. 35: 542-559.

Goldberg, M. F., C. Bruce, I. Ungerleider, and M. Mishkin (1982) Role of the striate cortex in the generation of smooth pursuit eye movements. Ann. Neurol. 12: 113.

Heywood, S., and J. Churcher (1971) Eye movements and the afterimage-I. Tracking the afterimage. Vision Res. 11: 1163-1168.

Heywood, S., and J. Churcher (1981) Saccades to step-ramp stimuli. Vision Res. 21: 479-490.

Hoffmann, K.-P. (1981) Neuronal responses related to optokinetic nystagmus in the cat's nucleus of the optic tract. In Progress in Oculomotor Research, A. F. Fuchs and W. Becker eds., pp. 443-454, Elsevier North-Holland, New York.

Hoffmann, K.-P. (1985) Direction selective cells in the nucleus of the optic tract in the squirrel monkey. Soc. Neurosci. Abstr. 11: 1009.

Hubel, D. H., and T. N. Wiesel (1968) Receptive fields and functional architecture of monkey striate cortex. J. Physiol. (Lond.) 195: 215243.

Judge, S. J., B. J. Richmond, and F. C. Chu (1980) Implantation of magnetic search coils for measurement of eye position: An improved method. Vision Res. 20: 535-538.

Knapp, H. D., E. Taub, and A. J. Berman (1963) Movements in monkeys with deafferented forelimbs. Exp. Neurol. 7: 305-315.

Kommerell, G., and R. Täumer (1972) Investigations of the eye tracking system through stabilized retinal images. Bibl. Ophthalmol. 82: $288-297$.

Lisberger, S. G., and L. E. Westbrook (1985) Properties of visual inputs that initiate horizontal smooth pursuit eye movements in monkeys. J. Neurosci. 5: 1662-1673.

Lisberger, S. G., C. Evinger, W. Johanson, and A. F. Fuchs (1981) Relationship between eye acceleration and retinal image velocity during foveal smooth pursuit in man and monkey. J. Neurophysiol. 46: 229-249.

Maunsell, J. H. R., and D. C. Van Essen (1983) The connections of the middle temporal visual area (MT) and their relationship to a cortical hierarchy in the macaque monkey. J. Neurosci. 3: 2563-2586.

Mikami, A., W. T. Newsome, and R. H. Wurtz (1986a) Motion selectivity in macaque visual cortex. I. Mechanisms of direction and speed selectivity in extrastriate area MT. J. Neurophysiol. 55: 13081327.

Mikami, A., W. T. Newsome, and R. H. Wurtz (1986b) Motion selectivity in macaque visual cortex. II. Spatio-temporal range of directional interactions in MT and V1. J. Neurophysiol. 55: 1328-1339.

Mohler, C. W., and R. H. Wurtz (1977) Role of striate cortex and superior colliculus in visual guidance of saccadic eye movements in monkeys. J. Neurophysiol. 40: 74-94.

Mustari, M. J., A. F. Fuchs, and J. Wallman (1985) Visual and oculomotor response properties of single units in the pretectum of the behaving rhesus macaque. Soc. Neurosci. Abstr. 11: 78.

Newsome, W. T., R. H. Wurtz, M. R. Dürsteler, and A. Mikami (1985) Deficits in visual motion processing following ibotenic acid lesions of the middle temporal visual area of the macaque monkey. J. Neurosci. 5: 825-840.

Newsome, W. T., A. Mikami, and R. H. Wurtz (1986) Motion selectivity in macaque visual cortex. III. Psychophysics and physiology of apparent motion. J. Neurophysiol. 55: 1340-1351.

Optican, L. M., D. S. Zee, and F. C. Chu (1985) Adaptive response to ocular muscle weakness in human pursuit and saccadic eye movements. J. Neurophysiol. 54: 110-122.

Pasik, P., T. Pasik, J. Hamori, and J. Szentagothai (1973) Golgi type II interneurons in the neuronal circuit of the monkey lateral geniculate nucleus. Exp. Brain Res. 17: 18-34.

Pola, J., and H. J. Wyatt (1980) Target position and velocity: The stimuli for smooth pursuit eye movements. Vision Res. 20:523-534.

Rabiner, L. R., and B. Gold (1975) Theory and Application of Digital Signal Processing, Prentice-Hall, New Jersey.

Rashbass, C. (1961) The relationship between saccadic and smooth tracking eye movements. J. Physiol. (Lond.) 159: 326-338.

Robinson, D. A. (1963) A method of measuring eye movement using a scleral search coil in a magnetic field. IEEE Trans. Biomed. Eng. 10: 137-145.

Robinson, D. A. (1965) The mechanics of human smooth pursuit eye 
movement. J. Physiol. (Lond.) 180: 569-591.

Robinson, D. A. (1973) Models of the saccadic eye movement control system. Kybernetik 14: 71-83.

Rodman, H. R., C. G. Gross, and T. D. Albright (1985) Removal of striate cortex does not abolish responsiveness of neurons in visual area MT of the macaque. Soc. Neurosci. Abstr. 11: 1246.

Schiller, P. H., and F. Koerner (1971) Discharge characteristics of single units in superior colliculus of the alert rhesus monkey. J. Neurophysiol. 34: 920-936.

Segraves, M. A., S.-Y. Deng, C. J. Bruce, L. G. Ungerleider, M. Mishkin, and M. E. Goldberg (1983) Monkeys with striate lesions have saccadic dysmetria to moving targets. Invest. Ophthalmol. Vis. Sci. (Suppl.) 24: 25 .

Segraves, M. A., M. E. Goldberg, S.-Y. Deng, C. J. Bruce, L. G. Ungerleider, and M. Mishkin (1986) No notion of motion: Permanent velocity deficits induced by unilateral striate lesions in the monkey. In Adaptive Process in the Visual and Oculomotor Systems, E. Keller and D. Zee, eds., pp. 217-221, Pergamon, New York.

Sparks, D. L., and R. Holland (1975) Computer control of eye position and velocity. Behav. Res. Methods Instrum. 7: 115-119.

Sprague, J. M. (1966) Interaction of cortex and superior colliculus in mediation of visually guided behavior in the cat. Science 153:1544 1547.

Sterling, P., and B. Wickelgren (1969) Visual receptive fields in the superior colliculus of the cat. J. Neurophysiol. 32: 1-15.

Tusa, R. J., D. S. Zee, and S. J. Herdman (1986) Recovery of oculomotor function in monkeys with large unilateral cortical lesions. In Adaptive Processes in the Visual and Oculomotor Systems, E. Keller and D. Zee, eds., pp. 209-216, Pergamon, New York.

Ungerleider, L. G., and R. Desimone (1986) Cortical connections of visual area MT in the macaque. J. Comp. Neurol. 248: 190-222.

Ungerleider, L. G., and M. Mishkin (1979) The striate projection zone in the superior temporal sulcus of Macaca mulatta: Location and topographic organization. J. Comp. Neurol. 188: 347-366.

Van Essen, D. C., and J. H. R. Maunsell (1983) Hierarchical orga- nization and functional streams in the visual cortex. Trends Neurosci. 6: 370-375.

Van Gisbergen, J. A. M., D. A. Robinson, and S. Gielen (1981) A quantitative analysis of generation of saccadic eye movements for burst neurons. J. Neurophysiol. 45: 417-442.

Wong-Riley, M. T. T. (1976) Projections from the dorsal lateral geniculate nucleus to prestriate cortex in the squirrel monkey as demonstrated by retrograde transport of horseradish peroxidase. Brain Res. 109: 595-600.

Wurtz, R. H. (1969a) Comparison of effects of eye movements and stimulus movements on striate cortex neurons of the monkey. $J$. Neurophysiol. 32: 987-994.

Wurtz, R. H. (1969b) Visual receptive fields of striate cortex neurons in awake monkeys. J. Neurophysiol. 32: 727-742.

Wurtz, R. H., and W. T. Newsome (1985) Divergent signals encoded by neurons in extrastriate areas MT and MST during smooth pursuit eye movements. Soc. Neurosci. Abstr. 11: 1246.

Yukie, M., and E. Iwai (1981) Direct projection from the dorsal lateral geniculate nucleus to the prestriate cortex in macaque monkeys. J. Comp. Neurol. 201: 81-97.

Zee, D. S., P. H. Butler, L. M. Optican, R. J. Tusa, and G. Gücer (1982) Effects of bilateral occipital lobectomies on eye movements in monkeys: Preliminary observations. In Physiological and Pathological Aspects of Eye Movements, A. Roucoux and M. Crommelink, eds., pp. 225-232, Junk, Boston.

Zee, D. S., R. J. Tusa, S. J. Herdman, S. J. Butler, and G. Gücer (1986) The acute and chronic effects of bilateral occipital lobectomy upon eye movements in monkey. In Adaptive Processes in the Visual and Oculomotor Systems, E. Keller and D. Zee, eds., pp. 267-274, Pergamon, New York.

Zeki, S. M. (1976) The projections to the superior temporal sulcus from areas 17 and 18 in the rhesus monkey. Proc. R. Soc. Lond. [Biol.] 193: 199-207.

Zihl, J., D. von Cramon, and N. Mai (1983) Sclective disturbance of movement vision after bilateral brain damage. Brain 106: 313-340. 